\title{
An integrated fuzzy intuitionistic sustainability assessment framework for manufacturing supply chain: a study of UK based firms
}

\author{
Alok Choudhary ${ }^{1}$ (D) Arijit De ${ }^{2} \cdot$ Karim Ahmed $^{3} \cdot$ Ravi Shankar $^{1,4}$
}

(C) The Author(s) 2019

\begin{abstract}
The increasing importance of sustainability has put pressure on organisations to assess their supply chain sustainability performance, which requires a holistic set of key performance indicators (KPIs) related to strategic, tactical and operational decision making of firms. This paper presents a comprehensive set of KPIs for sustainable supply chain management using a mixed method approach including analysing data from the literature survey, content analysis of sustainability reports of manufacturing firms and expert interviews. A 3-level hierarchical model is developed by classifying the identified KPIs into key sustainability dimensions as well as key supply chain decision-making areas including strategic, tactical and operational. A novel multi-attribute decision-making (MADM) based sustainability assessment framework is proposed. The proposed framework integrates value focussed thinking (VFT), intuitionistic fuzzy (IF) Analytic Hierarchy Process (AHP) and IF Technique for Order of Preference by Similarity to Ideal Solution (TOPSIS) methods. The novelty of the research lies in (1) using a rigorous mixed method approach for KPIs identification and industrial validation (2) the development of a novel integrated intuitionistic sustainability assessment framework for decision making and (3) the innovative application of the proposed framework and associated methodologies in the context not explored before. The practical data on the performance ratings of various KPIs were obtained from the experts and a novel intuitionistic fuzzy TOPSIS was applied to benchmark the organisations for their sustainability performance. Furthermore, the case study shows the applicability of the proposed framework to evaluate and identify the problem areas of the organisations and yield guidance on KPIs by recognising the most significant areas requiring improvement. This research contributes to the practical implication by providing an innovative sustainability assessment framework for supply chain managers to evaluate and manage sustainability performance by making informed decisions related to KPIs.
\end{abstract}

Keywords Supply chain management · Sustainability · Values focussed thinking · Intuitionistic fuzzy analytic hierarchy process · Intuitionistic fuzzy TOPSIS

Ravi Shankar

ravi1@dms.iitd.ernet.in

Extended author information available on the last page of the article 


\section{Introduction}

The supply chain considering the triple bottom line including economic, environmental and societal dimensions of sustainability plays a vital role in achieving Sustainable Development Goals. Even though the area of sustainable supply chain management (SSCM) has received much attention from both quantitative and empirical modelling researchers within the last two decades, the research into the development of practical decision-making tools and frameworks for manufacturing supply chain sustainability is still evolving (Korpela et al. 2001; Soheilirad et al. 2017; Taleizadeh et al. 2018). Seuring and Müller (2008) provided critical attributes of sustainable supply chain management by identifying the simultaneous consideration of economic, environmental and social impacts of the supply chain. Similarly, Fahimnia et al. (2015) performed a review and bibliometric analysis of green supply chain management and stated the need for considering sustainability holistically within the supply chain. It is apparent that the firms are continuously striving to comply with the increasing regulatory pressure for environmental sustainability (Dangelico and Pujari 2010; Montabon et al. 2007). With sustainable development goals of the United Nations and pressure on firms to achieve these by 2030, there is a greater need than ever before to develop frameworks and methodologies to effectively measure and manage key performance indicators (KPIs) for sustainability performance evaluation and improvement of the organisations.

Enhancing sustainability performance has gained paramount importance among the supply chain managers (Beamon and Chen 2001; Esmaeilikia et al. 2016; Wang and Gunasekaran 2017). In a complex, challenging and continually changing business environment, supply chain managers are faced with the dilemma of making informed decisions that require inputs about the Key Performance Indicators (KPIs) (Chai et al. 2013). From the supply chain perspective, it is imperative to determine the key performance indicators (KPIs) from the environmental, social and economic dimensions as well as the operational, strategic and tactical decision-making levels. Organisational performance and its measurement are vastly covered in the literature from the perspective of green supply chain and environmental management yet overlooking the need to address the trade-off as well as the impact of social dimensions on organisation's performance (Oyemomi et al. 2016; Olugu et al. 2011). Several researchers such as Deshmukh and Sunnapwar (2013) and Genovese et al. (2014) identified indicators for implementing environmental green supply chain and accordingly established its performance measurement framework. However, these researches are limited to providing guidance related to a specific aspect of the supply chain, e.g. supplier selection or green supply chain with a focus on academic literature only. Therefore, a holistic framework comprising of a set of KPIs of the triple bottom line and including three levels (strategic, operational and tactical) of decision-making is needed to manage the sustainability performance of a manufacturing supply chain.

The use of KPIs to determine the sustainability performance of the manufacturing supply chain requires the involvement of uncertainty related to human judgement in decision making. Multi-criteria decision-making (MCDM) techniques take into account of the uncertainty associated with expert opinion in an endeavour to simplify the decision context (Cheng and Liu 2007; Banasik et al. 2016). MCDM methods ensure the weighing of the expert judgement, allowing the balancing of different criteria and supporting the decision makers' judgements (Alexander et al. 2014; Belton and Stewart 2010). The application of MCDM to determine the weights of the KPIs for sustainability implementation in the supply chain presents a novelty (De Brucker et al. 2013; Allevi et al. 2018), as this approach requires the identification of the essential factors within the supply chain (Govindan et al. 2017). However, weighing the KPIs and their significance falls short in supporting the 
managerial decision-making. This leads to the need of establishing a conceptual framework that aims to alleviate the subjectivity of the organisation's performance assessment criterion and establish possible ways for improving the organisation's sustainability performance.

Thus, the contribution of the paper is to (1) identify KPIs for the sustainable supply chain management (SSCM) through literature review, content analysis of industrial practices identified in the sustainability reports, experts opinions for validation of KPIs and obtaining their respective weights and significance levels; (2) propose a novel multi-attribute decision-making (MADM) based sustainability assessment framework, which integrates value focussed thinking (VFT), intuitionistic fuzzy (IF) Analytic Hierarchy Process (AHP) and IF Technique for Order of Preference by Similarity to Ideal Solution (TOPSIS) methods; (3) developing and employing intuitionistic fuzzy analytic hierarchy process (IFAHP) for determining the intuitionistic fuzzy weights associated with the KPIs and estimating the importance of each KPI for judging the performance of manufacturing organisation; (3) developing and applying Intuitionistic fuzzy TOPSIS in a novel manner to rank sustainability performance of different organisation on the basis of the KPIs; and (4) demonstrating the application of the sustainability assessment framework in the context of UK based organisations along with its validity through a robustness check. The research addresses the following interrelated research questions:

1. What are the KPIs essential for assessing the sustainability performance of the manufacturing supply chain?

2. How to determine the importance of each KPIs while ranking the sustainability performance of the organizations?

3. How the proposed sustainability assessment framework can be deployed for practical application in terms of helping the supply chain mangers to make informed decisions?

The remainder of the paper is organised as follows. Section 2 presents a literature review related to the key areas of this research to identify existing research gaps. Section 3 presents a conceptual framework for sustainability assessment using the proposed MADM methods. Section 4 describes integrated intuitionistic methodologies. Section 5 presents the application of the proposed framework and methodologies. Section 6 concludes this paper highlighting the limitations of the study and proposing future research directions.

\section{Literature review}

This section is comprised of three parts. The first part reviews the literature in the domain of key performance indicators used in the context of sustainable supply chain management. The second part specifically reviews the research related to the application of intuitionistic fuzzy (IF) MCDM methods. Based on the literature review, the final part identifies research gaps in the current literature.

\subsection{Key performance indicators}

Performance evaluation of supply chains has been a managerial focus since the existence of supply chain management, and it is no different for supply chain managers concerned with sustainability. Initial works related to performance measurement have focused primarily on developing frameworks for estimating the organization's performance level while considering both qualitative and quantitative performance measures (Chan 2003). 
Further efforts have been made to establish supply chain performance evaluation metrics and in particular, there are a number of works that aims to estimate the performance measurements of green supply chains (Olugu et al. 2011). Within the literature many of the benefits of incorporating performance measurement into supply chain have been identified (Taticchi et al. 2013; Oyemomi et al. 2016) with much of the focus being on internal performance. Whilst these measures are evidently of importance, there is arguably a need to consider key performance indicators on a more holistic level which consider a range of sustainable supply chain activities (Ahi and Searcy 2015). Additionally, there is a need to develop effective methods to benchmark, correlate and assess sustainability practices (Taticchi et al. 2013).

The impact of environmental performance on the adoption of SSCM by companies, both financially and competitively, has been thoroughly analysed in the literature (Chen et al. 2017). Dubey et al. (2015) identified that institutional pressures, operational practices, and organizational managers, are seldom observed collectively. Montabon et al. (2007) identified that that there is a lack of proper evidence about measuring the organization's financial performance and its environmental performance together. Several research demonstrated that organization's commercial performance is positively correlated and directly proportional to environmental performance (Montabon et al. 2007; Iraldo et al. 2009). Thus, in accordance with the set parameters outlined by governments and regulatory authorities, organizations have adopted various metrics for assessing environmental performance (Dangelico and Pujari 2010). It is noteworthy that the limited volume of research that addresses the relationship between organizational competitiveness and environmental performance has been conducted solely from the perspective of organizational profitability (Fahimnia et al. 2015). According to dictionary definitions, "metrics" refers to a standard of measurement, while a "Key Performance Indicator" refers to a quantifiable measure utilized for evaluating organizational success in meeting outlined objectives (Reh 2016). In reviewing previous research, many issues, perspectives and criteria of SSCM as well as environmental impacts on organizations have been identified. Table 1 presents information of the key performance indicators in terms of their description and the literature sources from where the KPIs are obtained. After reviewing the literature, several KPIs and measures were recognized and collated in Table 1. It has been identified that future references refer to the subsequent references, and any overlaps were removed, with KPIs being primarily limited to their first initiating research. This also further shows the different perspectives from which SSCM has been evaluated.

After obtaining the KPIs from the abovementioned literature, it is also evident that there is a need of comprehensive set of key performance indicators along with their relative importance; at strategic, tactical and operational levels, reflecting a holistic view of SSCM performance. Most performance evaluation frameworks begin by identifying areas where performance should be measured, typically done by reviewing literature and it lacks consideration of specialist knowledge, whilst the approach considers multiple supply chain aspects taking into account of expert's knowledge. However, determining the relative importance of KPIs is a challenging task, given their conflicting nature and hence there is a need of rigourous approaches such as MCDM methods (Garg et al. 2014). Due to the inherent weakness of MCDM methods in addressing uncertainty and vagueness of decision makers while providing preferential judgement, many researchers have combined fuzzy sets with MCDM methods (Tooranloo and Iranpour 2017). However, due to the fact that fuzzy based MCDM methods only takes into account the degree of agreement of decision makers' opinions and neglect their disagreement, which is a natural way of human thought process. This limitation of the existing methodologies prompted the authors to develop 


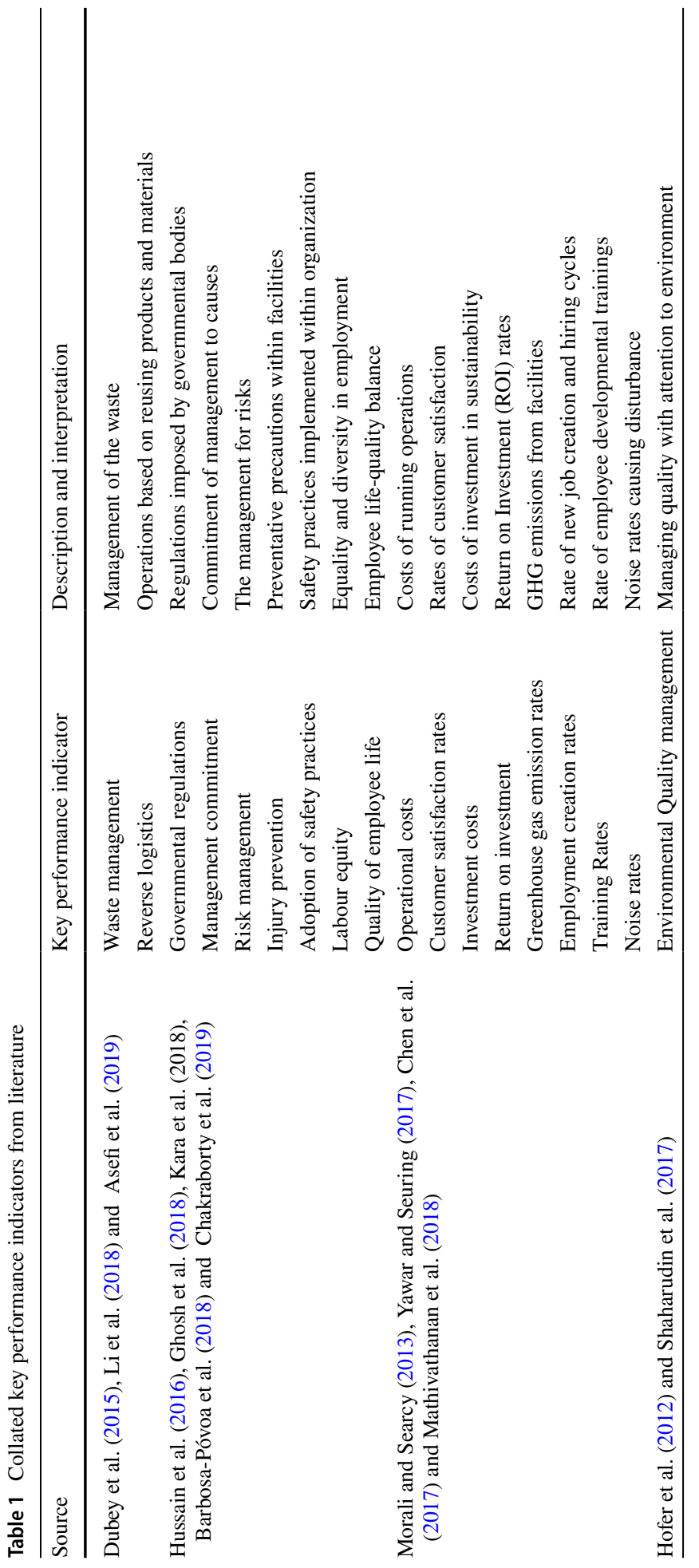




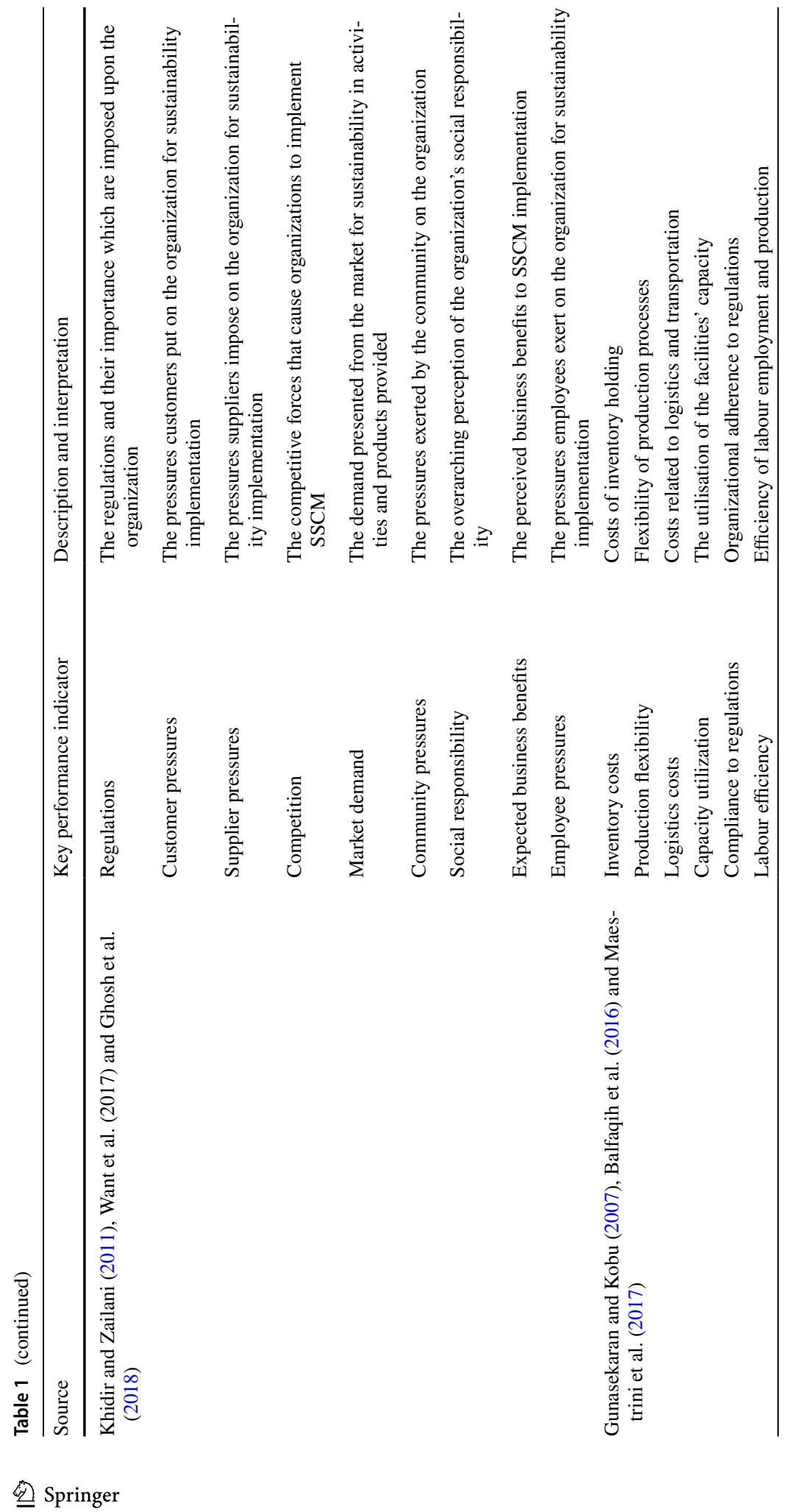




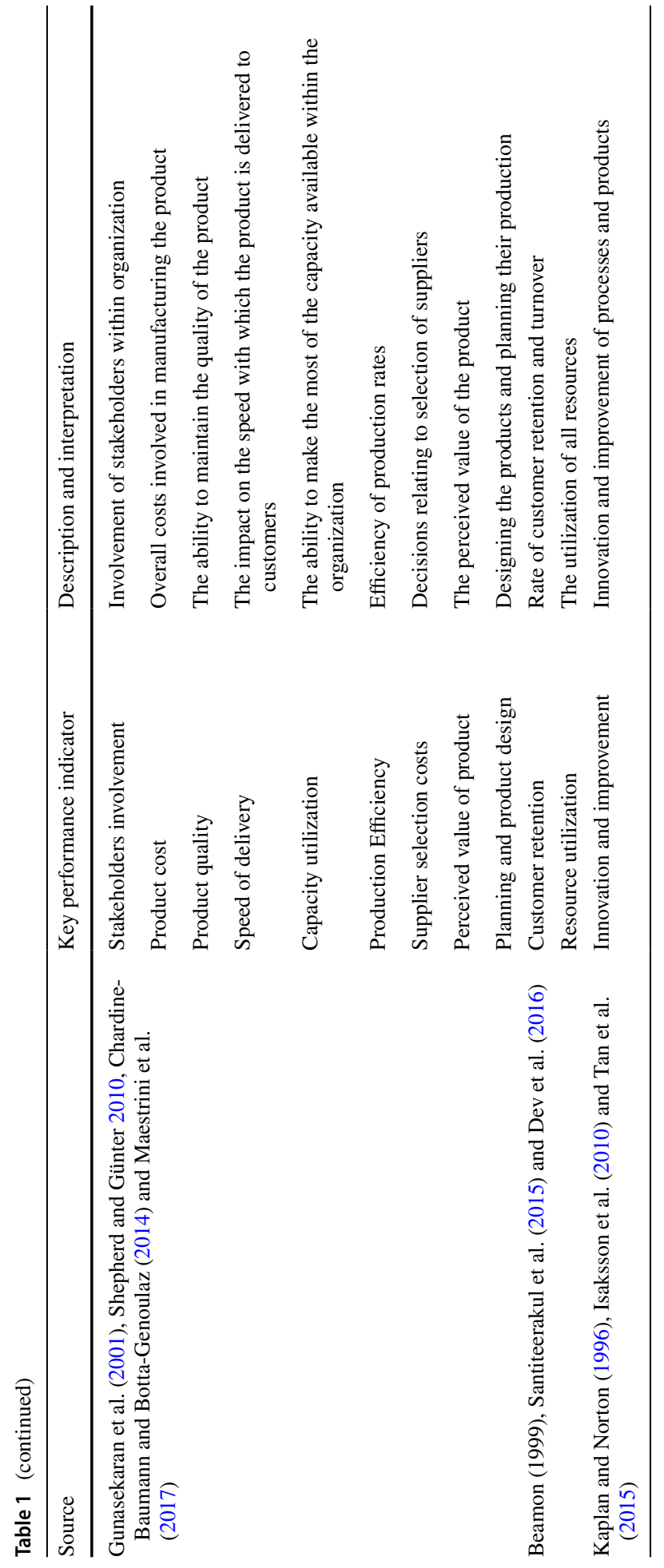


intuitionistic fuzzy sets based MCDM methods, which overcome the issues of the degree of disagreement in the present context of sustainable supply chain management.

\subsection{Intuitionistic multi criteria decision-making}

To overcome the shortcomings of fuzzy MCDM methods attributed to taking into account of human judgement in evaluating criteria and alternatives, as mentioned above, several researchers have introduced the concept of combining intuitionistic fuzzy sets with MCDM methods to provide more efficient decision support frameworks Tooranloo and Iranpour (2017) and Govindan and Jepsen (2016). Interestingly, most of the work is limited to supplier selection problems in the wider area of supply chain. Chang (2017) proposed a novel supplier selection method based on integrating the intuitionistic fuzzy weighted averaging method and the soft set with imprecise data. Tooranloo and Iranpour (2017) developed a supplier selection group decision framework employing interval intuitionistic fuzzy AHP method. Similarly, some researchers have combined intuitionistic fuzzy set with outranking methods. For example, Govindan and Jepsen (2016) addressed a supplier selection problem by employing trapezoidal intuitionistic fuzzy numbers integrated with ELECTRE. Similarly, Shen et al. (2015) extended the intuitionistic fuzzy ELECTRE III method taking into account group decision techniques and developed an automatic approach to achieve group opinion satisfaction. Moreover, Cao et al. (2015) proposed an intuitionistic fuzzy numbers for conducting pairwise comparison of criteria for green supplier selection and then used TOPSIS combined with intuitionistic fuzzy set to determine the rank of green suppliers. Besides the application of intuitionistic fuzzy set (IFS) based MCDM methods in supplier selection, few attempts were made to use this approach in other areas of supply chain. Qu et al. (2017) proposed an evaluation formula of intuitionistic fuzzy Choquet integral correlation coefficient between an alternative and the ideal alternative. They employed the proposed model to assess the green supply chain choice. Dong et al. (2015) used trapezoidal intuitionistic fuzzy numbers (TIFNs) to develop TIFN prioritized score, average, AND and OR operators to solve MCDM priority problem as well as applied the same in a supply chain collaboration case. It is evident from the above that the application of intuitionistic MCDM is relatively new in the SCM context with most of the literatures addressing supplier selection, risk assessment and green supply chain issues.

\subsection{Research gaps and contribution}

The literature review highlights the research gaps and a need to identify KPIs of sustainable supply chain management, which are essential to supply chain managers from the performance assessment perspective. Furthermore, considering the concept and definition of sustainable supply chain management, there is a need for further clarity and consistency related to the KPIs of SSCM (Taticchi et al. 2013; Oyemomi et al. 2016). Past research has focussed on green supply chain management or various aspects of environmental sustainability and has failed to consider the societal aspects of sustainability (Montabon et al. 2007; Dubey et al. 2015). Besides, the Key Performance Indicators (KPIs) need to be identified by taking into account the expert judgements. Based on the above research gaps, this paper aims to identify the KPIs impacting manufacturing organization's sustainability performance. A 3-level hierarchical model, which categories the key performance indicators on the basis of economic, environmental and social aspects, is presented in this paper. 
A framework is developed while considering the KPIs for assessing the sustainability performance of the manufacturing organizations. Intuitionistic Fuzzy AHP and intuitionistic fuzzy TOPSIS methodologies have been employed in different stages of the framework. It has been observed in the current literature that fuzzy AHP as MCDM method has its weakness in dealing with human judgement and consistency of preference relations. To deal with the current methodological shortcomings, a sustainability assessment framework is developed and incorporated with expert opinions coupled with intuitionistic fuzzy AHP based algorithm to improve the consistency of preference relations for determining the weights of the KPIs and their respective importance. Moreover, intuitionistic fuzzy TOPSIS is innovatively employed to rank different organisations on the basis of their performance on several essential KPIs.

\section{Framework for sustainability assessment}

This section provides a framework for identifying, assessing and prioritising the key performance indicators within sustainable supply chain management. Figure 1 presents the proposed conceptual framework associated with the overall process for the evaluation and assessment of

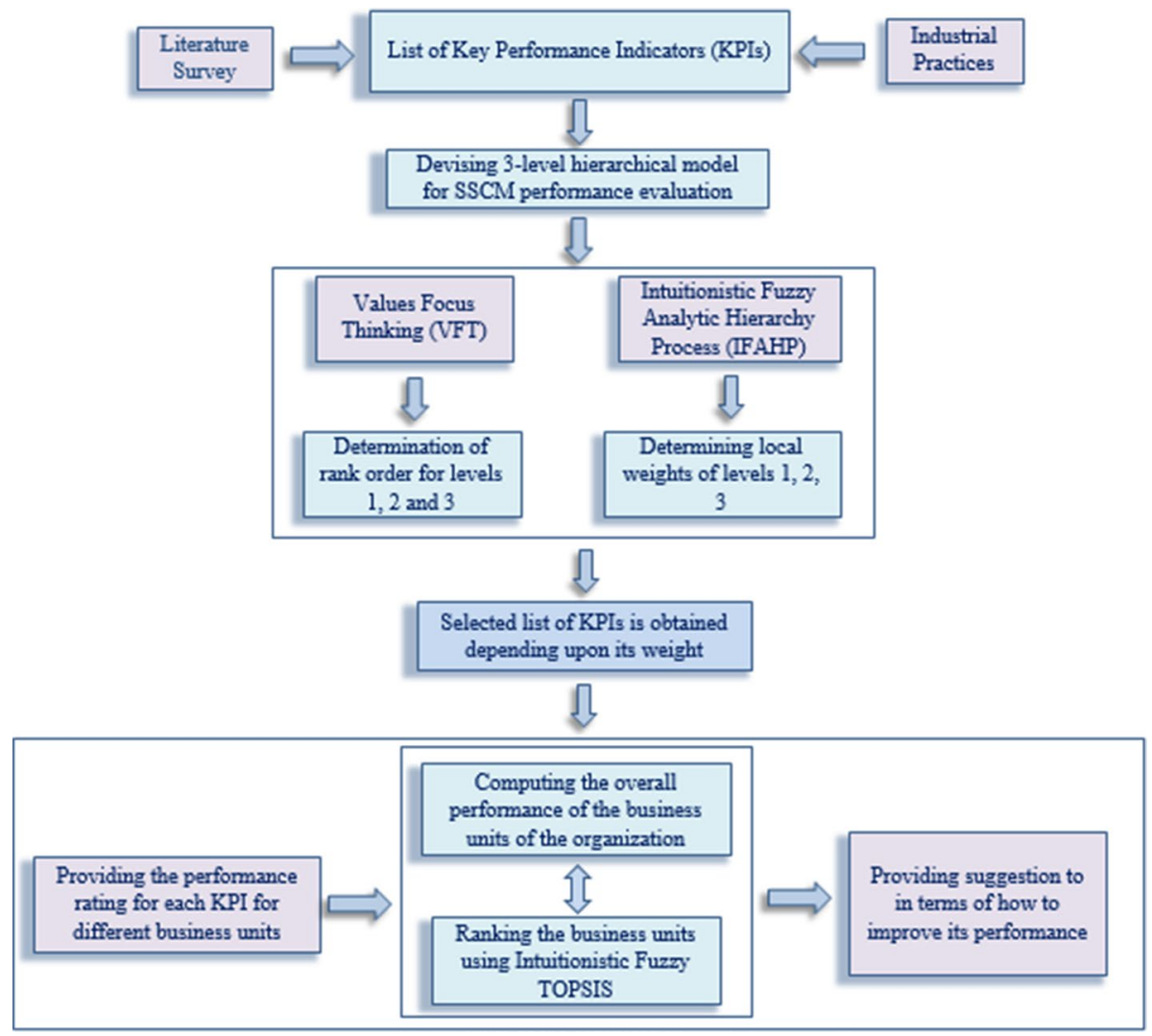

Fig. 1 Framework for assessing the sustainability performance of the organizations 
KPIs for sustainable supply chain management. This framework outlines the methodologies used at each stage which begins with the identification of KPIs. Based on this, a three-level hierarchical model is developed, which categorises the KPIs on the basis of Triple Bottom Line (TBL) and organisational decision-making levels. Table 2 presents the detailed list of the KPIs considering the three-level hierarchical model. Moreover, Table 2 helps to categorize the obtained KPIs into first level criteria of triple bottom line related to economic, environmental and social. Table 2 also helps to categorize the KPIs into second level criteria associated with organizational decision level such as operational decisions, strategic decisions and tactical decisions. Third level Criteria of Table 2 are the Key Performance Indicators which are selected by performing a thorough literature survey, content analysis of sustainability reports from a cross-section of manufacturing firms in the FTSE 500 list and experts opinion.

After obtaining the KPIs in the third level criteria, Values Focus Thinking (VFT) is conducted for ranking each of the levels based on the preferences of the experts. Values Focus Thinking (VFT), a widely used method is applied to rank the Key Performance Indicators (KPIs) based on the initial opinions accumulated from the decision makers (Keeney 1996). Values-Focused thinking is conducted in a focus-group meeting with a pool of industry experts from the field who are attendees of the UK Forum for Supply Chain Sustainability and identified as per specific criteria including (1) experts should belong to a manufacturing organisation, (2) experts should have a track record of credentials in implementing sustainability in supply chain (3) experts should have a decision making role in their organisations. It is imperative to note that the respondents are asked to give a ranking score of importance of 1-5 on a Likert scale for each KPI presented within the survey, where 1 is the most important and 5 is the least important. The results obtained from VFT approach need a further ratification of the choices and "decisions" made.

As discussed earlier, intuitionistic fuzzy analytic hierarchy process (IFAHP) is the most widely used approach to deal with the ambiguity and complexity of the decision-making process, especially over several hierarchical levels of decisions. Intuitionistic fuzzy analytic hierarchy process (IFAHP) is employed to determine the weights of the KPIs and based on the relative weights a selected group of KPIs are identified. Intuitionistic fuzzy analytic hierarchy process is used to compute the local weights for hierarchical levels 1, 2 and 3. Based on the local weights for the 3rd level KPIs, the importance of each KPIs are obtained. Revised list of KPIs is determined comprises of the KPIs whose importance value is more than a certain threshold limit. The revised list of KPIs obtained is used for the performance evaluation framework.

The data associated with the performance ratings for the selected list of KPIs are obtained for several organisations, and accordingly, the overall performance of the organization is determined. The organization's performance is determined by considering the combined performance level of the selected group of KPIs. The organisations are ranked using intuitionistic fuzzy TOPSIS based on their performance on different KPIs. Several suggestions are provided to the organisations regarding the possible scope of improvement from the perspective of the performance of the KPIs. The next section illustrates about the intuitionistic fuzzy analytic hierarchy process which is used to obtain the weight for each KPIs. 


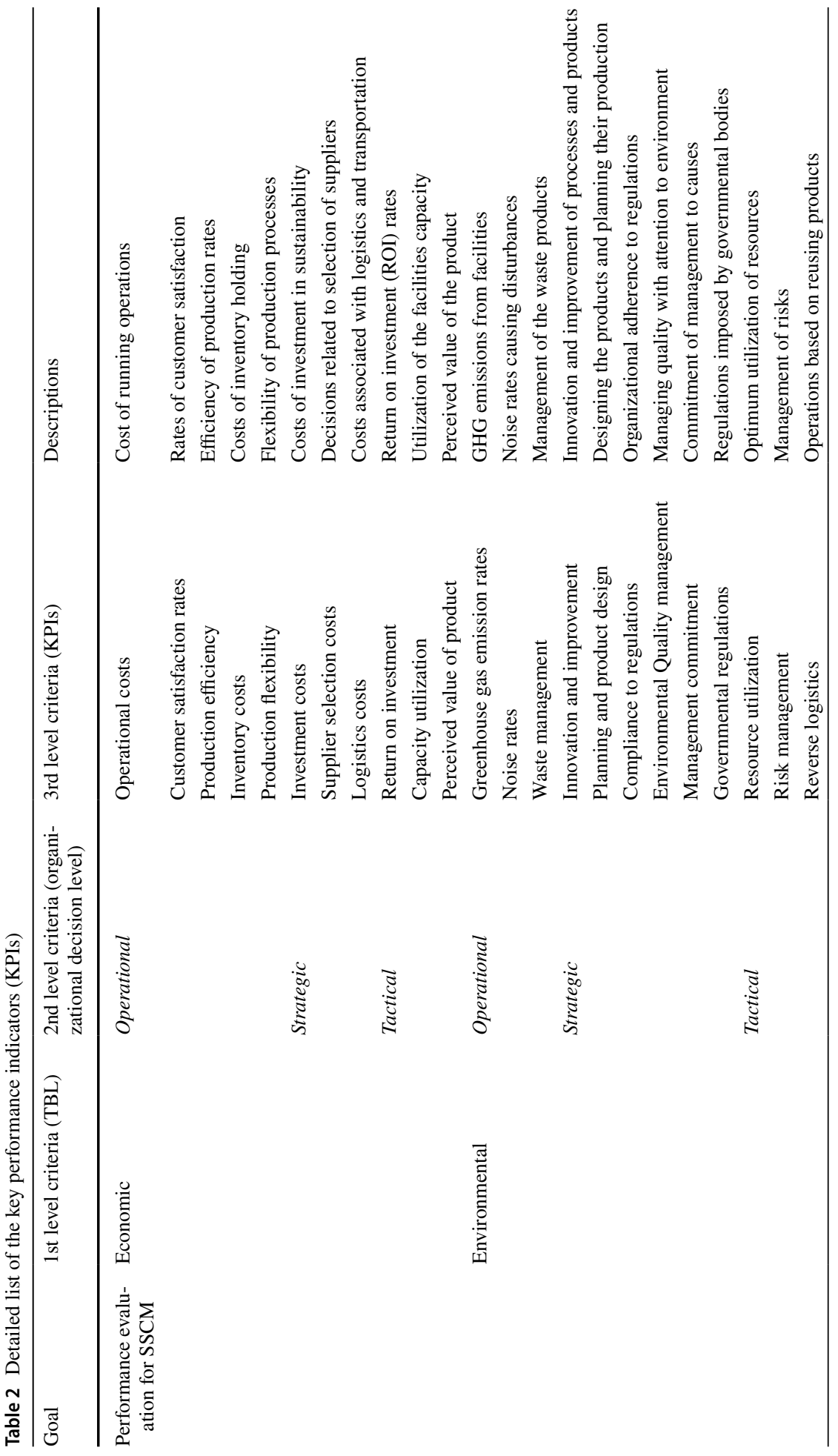




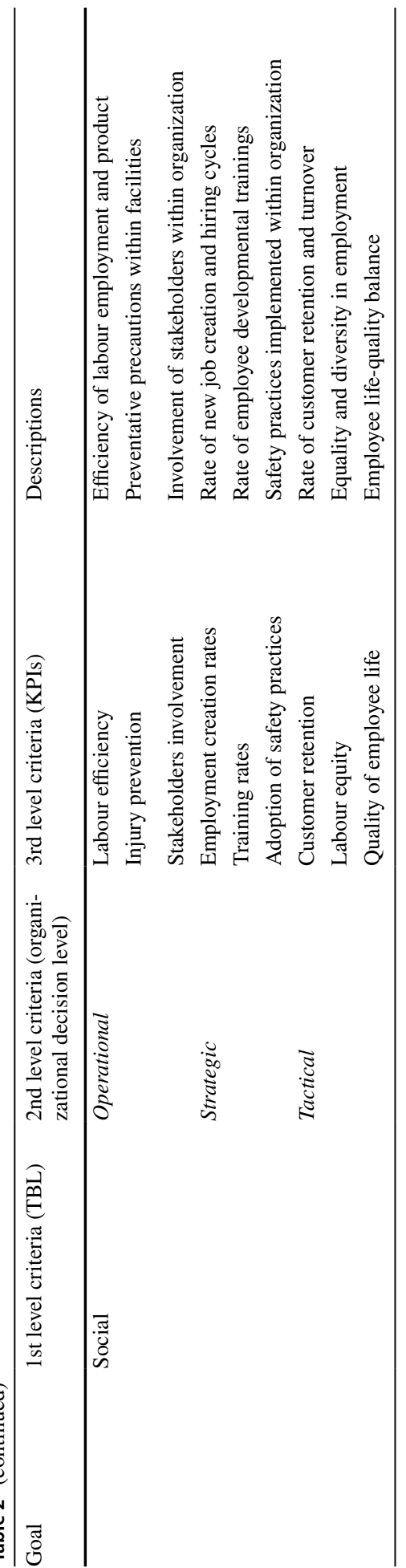

Springer 


\section{Intuitionistic fuzzy set combined with MCDM techniques}

Atannassov (1999) introduced the concept of intuitionistic fuzzy set, which contains the information related to membership, non-membership and hesitancy function. The intuitionistic fuzzy set has shown definite advantages in handling vagueness and uncertainty associated with human judgement (Xu and Liao 2014). Given that the preferences are essentially judgements of humans which are based on perceptions, therefore it is essential to employ intuitionistic fuzzy set theory combined with analytical hierarchy process which addresses the vagueness associated with human judgement (Xu and Liao 2014). Intuitionistic fuzzy set is characterized by a membership function, a non-membership function and a hesitancy function (Xu and Liao 2014). Let $Y$ be a crisp set which is assumed to be fixed and suppose $b \subset Y$ is a fixed set. Therefore, an intuitionistic fuzzy set (IFS) $\widetilde{b}$ can be represented in the following way,

$$
\widetilde{b}=\left\{\left(y, \alpha_{b}(y), \beta_{b}(y)\right) \mid y \in Y\right\}
$$

The function $\alpha_{b}: E \rightarrow[0,1]$ is the degree of membership and $\beta_{b}: E \rightarrow[0,1]$ is defined as the degree of non-membership function of the element $y \in Y$. Moreover, for each $y \in Y$, the following relationship $0 \leq \alpha_{b}+\beta_{b} \leq 1$ holds true. For each intuitionistic fuzzy set $\widetilde{b}$ in the crisp set $Y$, the degree of non-determinacy (uncertainty) associated with the membership of the element $y \in Y$ can be expressed in the following way,

$$
\eta_{b}(y)=1-\alpha_{b}(y)-\beta_{b}(y)
$$

For ordinary fuzzy sets such triangular or trapezoidal fuzzy sets, the degree of nondeterminacy is zero for all the element $y \in Y$ or $\eta_{b}(y)=0$ for $\forall y \in Y . \eta_{b}(y)$ is the hesitance degree of $y$ and $\eta_{b}(y)$ should be considered while computing the distance between two intuitionistic fuzzy sets. It should be noted that the value of $\eta_{b}(y)$ lies with the range $[0,1]$ or $\eta_{b}(y) \in[0,1]$ for $\forall y \in Y$. An intuitionistic fuzzy value comprises of the following $\rho=\left(\alpha_{\rho}, \beta_{\rho}, \eta_{\rho}\right)$, where $\alpha_{\rho} \in[0,1], \beta_{\rho} \in[0,1], \eta_{\rho} \in[0,1]$ and $\alpha_{\rho}+\beta_{\rho} \leq 1$.

\subsection{Intuitionistic preference relation}

An intuitionistic preference relation $v$ related to the set $Y=\left\{y_{1}, y_{2}, \ldots, y_{m}\right\}$ can be expressed in the following way, $v=\left(v_{p q}\right)_{m \times m}=\left[\begin{array}{cccc}\alpha_{11}, \beta_{11} & \alpha_{12}, \beta_{12} & \cdots & \alpha_{1 m}, \beta_{1 m} \\ \alpha_{21}, \beta_{21} & \alpha_{22}, \beta_{22} & \cdots & \alpha_{2 m}, \beta_{2 m} \\ \vdots & \vdots & \vdots & \vdots \\ \alpha_{m 1}, \beta_{m 1} & \alpha_{m 2}, \beta_{m 2} & \cdots & \alpha_{m m}, \beta_{m m}\end{array}\right]$. Here, $v_{p q}=\left(\alpha_{p q}, \beta_{p q}\right)$

and $\alpha_{p q}$ provides the degree up to which $y_{p}$ is preferred over $y_{p}$ and $\beta_{p q}$ denotes the degree up to which $y_{p}$ is not preferred over $y_{p}$. Indeterminacy degree or hesitancy degree can be computed using the following relationship,

$$
\eta\left(y_{p}, y_{q}\right)=1-\alpha\left(y_{p}, y_{q}\right)-\beta\left(y_{p}, y_{q}\right)
$$

The following conditions need to be satisfied for determining hesitancy degree using Eq. (3),

$$
\left.\begin{array}{r}
\alpha_{p q}, \beta_{p q} \in[0,1], \alpha_{p q}+\beta_{p q} \leq 1, \alpha_{p q}=\beta_{q p}, \beta_{p q}=\alpha_{q p} \\
\alpha_{p p}=\beta_{p p}=0.5, \eta_{p q}=1-\alpha_{p q}-\beta_{p q}
\end{array}\right\} \quad p, q=1,2, \ldots, n
$$


The consistency associated with the intuitionistic preference relation matrix need to be checked and repaired if certain inconsistency is observed. Maintain the appropriate consistency is essential within preference relations as the lack of consistency may lead to misleading solutions. The consistency is validated by adopting a property called multiplicative consistency proposed by Xu et al. (2014). An intuitionistic preference relation $v=\left(v_{p q}\right)_{m \times m}$, where $v_{p q}=\left(\alpha_{p q}, \beta_{p q}\right)$ and $p, q=1,2, \ldots, n$, becomes a multiplicative consistent by satisfying the following conditions.

$$
\begin{aligned}
& \alpha_{p q}=\left\{\begin{array}{ll}
0, & \text { if }\left(\alpha_{p r}, \alpha_{r q}\right) \in\{(0,1),(1,0)\} \\
\frac{\alpha_{p r} \alpha_{r q}}{\alpha_{p r} \alpha_{r q}+\left(1-\alpha_{p r}\right)\left(1-\alpha_{r q}\right)}, & \text { otherwise }
\end{array}\right\} \text { for all } p \leq r \leq q \\
& \beta_{p q}=\left\{\begin{array}{ll}
0, & \text { if }\left(\beta_{p r}, \beta_{r q}\right) \in\{(0,1),(1,0)\} \\
\frac{\beta_{p r} \beta_{r q}}{\beta_{p r} \beta_{r q}+\left(1-\beta_{p r}\right)\left(1-\beta_{r q}\right)}, & \text { otherwise }
\end{array}\right\} \text { for all } p \leq r \leq q
\end{aligned}
$$

When $\left(\alpha_{p r}, \alpha_{r q}\right) \in\{(0,1),(1,0)\}$, that means $\left(\alpha_{p r}, \alpha_{r q}\right)=(0,1)$ or $\left(\alpha_{p r}, \alpha_{r q}\right)=(1,0)$ or both hold true, then the denomination of Eq. (5) will be zero or $\alpha_{p r} \alpha_{r q}+\left(1-\alpha_{p r}\right)\left(1-\alpha_{r q}\right)=0$. Thus, $\alpha_{p q}=0$ and $\beta_{p q}=0$, when $\left(\alpha_{p r}, \alpha_{r q}\right) \in\{(0,1),(1,0)\}$ and $\left(\beta_{p r}, \beta_{r q}\right) \in\{(0,1),(1,0)\}$ respectively.

\subsection{Procedure of intuitionistic fuzzy analytic hierarchy process (IFAHP)}

The procedure of IFAHP as given in Xu and Liao (2014) can be described in the following steps,

Step 1 Obtain the intuitionistic preference relation $v=\left(v_{p q}\right)_{m \times m}$ for all the criteria from the decision makers. Here, $v_{p q}=\left(\alpha_{p q}, \beta_{p q}\right)$, where $\alpha_{p q}$ is the degree of preferring criteria $y_{p}$ over criteria $y_{p}$ and $\beta_{p q}$ is the degree of not preferring criteria $y_{p}$ over criteria $y_{q}$.

Determining the intuitionistic preference relations via the pairwise comparison between each criterion and sub-criteria. Moreover, the alternatives are compared under each criteria or sub-criteria, and then, the intuitionistic preference relations are constructed (Xu and Liao (2014)).

Step 2 Determining the perfect multiplicative consistent intuitionistic preference relation,

$\bar{v}=\left(\bar{v}_{p q}\right)_{m \times m}=\left[\begin{array}{ccccc}\bar{\alpha}_{11}, \bar{\beta}_{11} & \bar{\alpha}_{12}, \bar{\beta}_{12} & . . & \bar{\alpha}_{1 m}, \bar{\beta}_{1 m} \\ \bar{\alpha}_{21}, \bar{\beta}_{21} & \bar{\alpha}_{22}, \bar{\beta}_{22} & . . & \bar{\alpha}_{2 m}, \bar{\beta}_{2 m} \\ : & : & : & : \\ \bar{\alpha}_{m 1}, \bar{\beta}_{m 1} & \bar{\alpha}_{m 2}, \bar{\beta}_{m 2} & . . & \bar{\alpha}_{m m}, \bar{\beta}_{m m}\end{array}\right]$ using Eqs. (7) and (8). For $\forall q$ and $\forall p$,

if $q>p+1$, then $\bar{v}_{p q}=\left(\bar{\alpha}_{p q}, \bar{\beta}_{p q}\right)$ where $\bar{\alpha}_{p q}$ and $\bar{\beta}_{p q}$ can be computed using the following expressions,

$$
\bar{\alpha}_{p q}=\frac{\sqrt[(q-p-1)]{\prod_{r=p+1}^{q-1} \alpha_{p r} \alpha_{r q}}}{\sqrt[(q-p-1)]{\prod_{r=p+1}^{q-1} \alpha_{p r} \alpha_{r q}}+\sqrt[(q-p-1)]{\prod_{r=p+1}^{q-1}\left(1-\alpha_{p r}\right)\left(1-\alpha_{r q}\right)}}
$$




$$
\bar{\beta}_{p q}=\frac{\sqrt[(q-p-1)]{\prod_{r=p+1}^{q-1} \beta_{p r} \beta_{r q}}}{\sqrt[(q-p-1)]{\prod_{r=p+1}^{q-1} \beta_{p r} \beta_{r q}}+\sqrt[(q-p-1)]{\prod_{r=p+1}^{q-1}\left(1-\beta_{p r}\right)\left(1-\beta_{r q}\right)}}
$$

When $p>q+1$, then $\bar{\alpha}_{p q}=\bar{\beta}_{q p}$ and $\bar{\beta}_{p q}=\bar{\alpha}_{q p}$. For rest of the scenarios, $\bar{\alpha}_{p q}=\alpha_{p q}$ and $\bar{\beta}_{p q}=\beta_{p q}$.

Step 3 Determining the distance measure between the given intuitionistic preference relation $v=\left(v_{p q}\right)_{m \times m}$ and its corresponding perfect multiplicative consistent intuitionistic preference relation $\bar{v}=\left(\bar{v}_{p q}\right)_{m \times m}$. The distance measure can be computed using the following equation,

$\operatorname{Dist}(\bar{v}, v)=\frac{1}{2(m-1)(m-2)} \sum_{p=1}^{m} \sum_{q=1}^{m}\left(\left|\bar{\alpha}_{p q}-\alpha_{p q}\right|+\left|\bar{\beta}_{p q}+\beta_{p q}\right|+\left|\bar{\eta}_{p q}-\eta_{p q}\right|\right)$

here $m$ is the number of criteria and $\eta_{p q}$ is the hesitance degree. $\eta_{p q}$ is determined using the relationship, $\eta_{p q}=1-\alpha_{p q}-\beta_{p q}$ and the value of $\eta_{p q}$ lies with $(0,1)$.

Step 4 Suppose $K$ is the maximum number of iteration. So, considering $k<K$, where $k$ is the current iteration. At first, the distance measure between $V$ and $\bar{V}$ computed using Eq. (9) is checked. If $\operatorname{Dist}(\bar{v}, v)>\lambda$ (here, $\lambda$ is the consistency threshold), it means the intuitionistic preference relation is within unacceptable consistency and the algorithm moves on to step 5 (Xu and Liao 2014). Otherwise (when Dist $(\bar{v}, v)<\lambda$ or distance measure is less than the consistency threshold or the intuitionistic preference relation is within the acceptable consistency (Xu et al. 2014)), stop the iteration and move on to step 7 and consider $v$ as the output.

Step 5 Repair the inconsistent intuitionistic preference relations as mentioned in $\mathrm{Xu}$ and Liao (2014). IFAHP presented a novel way to ensure the consistency by automatically repairing the inconsistent intuitionistic preference relation, which do not need much participation from the decision maker (Xu and Liao 2014). For perform-

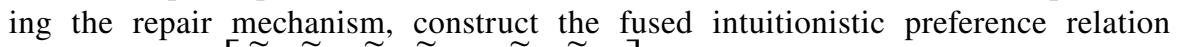

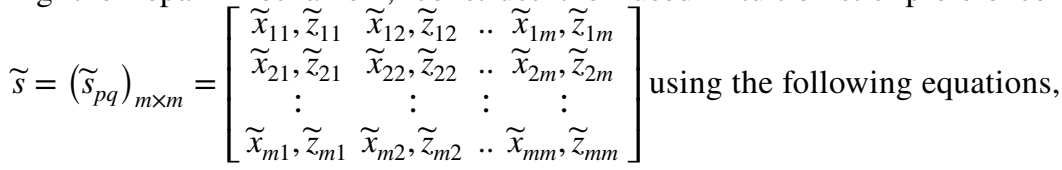

$$
\begin{aligned}
& \tilde{x}_{p q}=\frac{\left(\alpha_{p q}\right)^{(1-\delta)}\left(\bar{\alpha}_{p q}\right)^{\delta}}{\left(\alpha_{p q}\right)^{(1-\delta)}\left(\bar{\alpha}_{p q}\right)^{\delta}+\left(1-\alpha_{p q}\right)^{(1-\delta)}\left(1-\bar{\alpha}_{p q}\right)^{\delta}} \\
& \tilde{z}_{p q}=\frac{\left(\beta_{p q}\right)^{(1-\delta)}\left(\bar{\beta}_{p q}\right)^{\delta}}{\left(\beta_{p q}\right)^{(1-\delta)}\left(\bar{\beta}_{p q}\right)^{\delta}+\left(1-\beta_{p q}\right)^{(1-\delta)}\left(1-\bar{\beta}_{p q}\right)^{\delta}}
\end{aligned}
$$


where $\tilde{s}_{p q}=\left(\bar{x}_{p q}, \bar{z}_{p q}\right)$ for $p, q=1,2, \ldots, n$ and $\delta$ is the controlling parameter and for smaller value of $\delta$, the fused intuitionistic preference relation of $k^{\text {th }}$ iteration, $\tilde{s}^{k}=\left(\widetilde{s}_{p q}^{k}\right)_{m \times m}$ is more closer to the $v^{k}$. Here, $v^{k+1}=\widetilde{s}^{k}$ or $\alpha_{p q}^{k+1}=\widetilde{x}_{p q}^{k}$ and $\beta_{p q}^{k+1}=\widetilde{z}_{p q}^{k}$.

The repair mechanism approach presented by $\mathrm{Xu}$ and Liao (2014)is adopted over here for ensuring the consistency of intuitionistic preference relation and moreover improving the consistency automatically.

Step 6 Now, compute the distance measure between the infused intuitionistic preference relation $v^{k+1}$ (which is the $\widetilde{s}^{k}$ determined in step 5) and perfect multiplicative consistent intuitionistic preference relation $\bar{v}$. Move to step 4 for comparing the distance measure with the consistency threshold.

Step 7 Based on the operational laws of intervals, a new normalizing rank summation method is given by $\mathrm{Xu}$ and Liao (2014) to derive the priority weights. Now, determining the priority weights $w_{i}=\left(w_{1}, w_{2}, \ldots, w_{m}\right)$ for the intuitionistic preference relation $v=\left(v_{p q}\right)_{m \times m}, v_{p q}=\left(\alpha_{p q}, \beta_{p q}\right)$ using the following equations,

$$
w_{i}=\left(\frac{\sum_{q=1}^{m} \alpha_{p q}}{\sum_{p=1}^{m} \sum_{q=1}^{m}\left(1-\beta_{p q}\right)}, 1-\frac{\sum_{q=1}^{m}\left(1-\beta_{p q}\right)}{\sum_{p=1}^{m} \sum_{q=1}^{m} \alpha_{p q}}\right)
$$

Figure 2 presents the pseudo-code associated with the algorithm for intuitionistic fuzzy analytic process. Section 4.3 presents an example of determining the weights using intuitionistic fuzzy analytic hierarchy process (IFAHP) for the KPIs associated with environmental-strategic.

\subsection{Intuitionistic fuzzy TOPSIS}

The methodology adopted in this paper combines intuitionistic fuzzy AHP with intuitionistic fuzzy TOPSIS which are adopted from the research work of Xu and Liao (2014), Yue (2014) and Cheng et al. (2017). Intuitionistic fuzzy AHP presented in Sect. 4.2 aims to perform the pair wise comparison of criteria for determining the criteria weights while employing the novel repair mechanism for correcting multiplicative consistency of decision matrices. The intuitionistic fuzzy TOPSIS presented in this section aims to obtain the rank for the alternatives while considering the specific set of criteria. Intuitionistic fuzzy AHP and intuitionistic fuzzy TOPSIS have been used separately in the literature, although there no such research which presents an integrated strategy of combining intuitionistic fuzzy AHP with intuitionistic fuzzy TOPSIS. The procedure of intuitionistic fuzzy TOPSIS presented in Cheng et al. (2017) can be briefly described using the following steps,

Step 1 Obtaining the intuitionistic preference matrix from $M$ decision makers $\left(t_{1}, t_{2}, \ldots, t_{m}\right)$ considering $S$ alternatives $\left(a_{1}, a_{2}, \ldots, a_{s}\right)$ and $R$ criteria $\left(b_{1}, b_{2}, \ldots, b_{r}\right)$ and the decision matrix obtained can be represented as $\left(x_{s r}^{m}\right)_{S \times R}=\left(\tau_{s r}^{m}, \theta_{s r}^{m}\right)_{S \times R}$. The weights associated with each of the criteria for each of the decision makers can be represented in the following way, $w_{r}^{m}=\left(w_{1}^{m}, w_{2}^{m}, \ldots, w_{R}^{m}\right)$. The intuitionistic fuzzy matrix is obtained by using the criteria weights. 
Procedure: Intuitionistic Fuzzy AHP

1. Assign values for the parameters $\lambda, \delta$ and $K$ (Maximum number of iterations)

2. Provide the intuitionistic preference relation $v=\left(v_{p q}\right)_{m \times m}$

3. Determine the size of $v,[p, q]=\operatorname{size}(v)$

4. for $p=1$ to number of rows of matrix

5. for $q=1$ to number of coloumn of matrix

6. if $q>p+1$

7. Determine $\bar{\alpha}_{p q}$ and $\bar{\beta}_{p q}$ using equations (7) and (8) respectively

8. $\quad$ elseif $p>q+1$

9. $\quad$ Determine $\bar{\alpha}_{p q}$ and $\bar{\beta}_{p q}$ using the relationships, $\bar{\alpha}_{p q}=\bar{\beta}_{q p}$ and $\bar{\beta}_{p q}=\bar{\alpha}_{q p}$

10. else

11. Determine $\bar{\alpha}_{p q}$ and $\bar{\beta}_{p q}$ using the equations, $\bar{\alpha}_{p q}=\alpha_{p q}$ and $\bar{\beta}_{p q}=\beta_{p q}$

12. end

13. end

14.end

15.Compute the distance measure between $v$ and $\bar{v}$, Dist $(\bar{v}, v)$ using equation (9)

16. for $k=1$ to $K$ (Maximum number of iterations)

17. if distance measure is more than the consistency threshold $($ or, $\operatorname{Dist}(\bar{v}, v)>\lambda)$

18. for $p=1$ to number of rows of matrix

19. for $q=1$ to number of coloumn of matrix

20. Determine fused intuitionistic preference relation $\tilde{s}$ using equations (10) and (11)

21. end

22. end

23. Consider $\tilde{s}$ as the new intuitionistic preference relation or $v^{k+1}=\tilde{s}^{k}$

24. $\quad$ Estimate the distance measure between $v^{k+1}$ and $\bar{v}$, Dist $\left(\bar{v}, v^{k+1}\right)$ using equation (9)

25. $\quad$ Move on to the next iteration, $k=k+1$

26. else

27. Stop the iteration and consider $v^{k+1}$ as the output

28. end

29.end

30.Determine priority weights related to the output $v^{k+1}$ using the equation (12)

Fig. 2 Algorithm related to the intuitionistic fuzzy analytic process

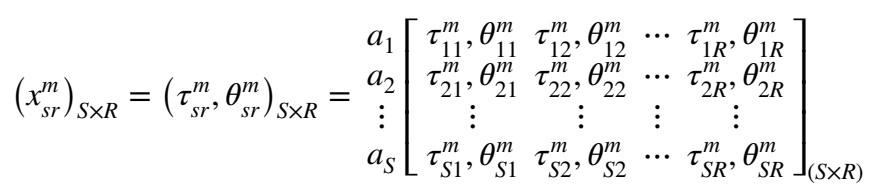

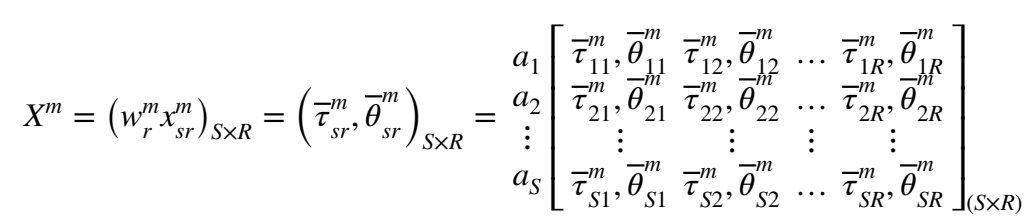

Equation (13) represents the intuitionistic fuzzy matrix obtained from $M$ decision makers and Eq. (14) presents the weighted intuitionistic fuzzy matrix obtained using the fol- 
lowing relationships, $\bar{\tau}_{s r}^{m}=1-\left(1-\tau_{s r}^{m}\right)^{w_{r}^{m}}$ and $\bar{\theta}_{s r}^{m}=\left(\theta_{s r}^{m}\right)^{w_{r}^{m}}$ which is adopted from the research work of Cheng et al. (2017).

Step 2 Determining the positive ideal decision matrix $X^{*}$, negative ideal decision matrix $X_{c}^{*}$, left individual negative ideal decision matrix $X_{u}^{-}$and right individual negative ideal decision matrix $X_{v}^{-}$in the following way,

$$
X^{*}=\left(x_{s r}^{*}\right)_{S \times R}=\left(\tilde{\tau}_{s r}^{*}, \widetilde{\theta}_{s r}^{*}\right)_{S \times R}=\begin{gathered}
a_{1} \\
a_{2} \\
\vdots \\
a_{S}
\end{gathered}\left[\begin{array}{cccccc}
\tilde{\tau}_{11}^{*}, \widetilde{\theta}_{11}^{*} & \widetilde{\tau}_{12}^{*}, \widetilde{\theta}_{12}^{*} & \ldots & \widetilde{\tau}_{1 R}^{*}, \widetilde{\theta}_{1 R}^{*} \\
\tilde{\tau}_{21}^{*}, \widetilde{\theta}_{21}^{*} & \widetilde{\tau}_{22}^{*}, \widetilde{\theta}_{22}^{*} & \ldots & \widetilde{\tau}_{2 R}^{*}, \widetilde{\theta}_{2 R}^{*} \\
\vdots & \vdots & \vdots & \vdots \\
\tilde{\tau}_{S 1}^{*}, \widetilde{\theta}_{S 1}^{*} & \widetilde{\tau}_{S 2}^{*}, \widetilde{\theta}_{S 2}^{*} & \ldots & \widetilde{\tau}_{S R}^{*}, \widetilde{\theta}_{S R}^{*}
\end{array}\right]_{(S \times R)}
$$

where $\widetilde{\tau}_{s r}^{*}=1-\prod_{m=1}^{M}\left(1-\bar{\tau}_{s r}^{m}\right)^{M}$ and $\widetilde{\theta}_{s r}^{*}=1-\prod_{m=1}^{M}\left(1-\bar{\theta}_{s r}^{m}\right)^{M}$.

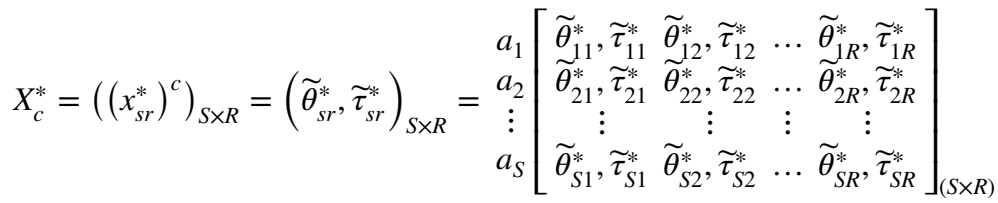

$\left(x_{s r}^{*}\right)^{c}$ is the compliment of $x_{s r}^{*}=\left(\widetilde{\tau}_{s r}^{*}, \widetilde{\theta}_{s r}^{*}\right)$, or $\left(x_{s r}^{*}\right)^{c}$ can be represented as $\left(x_{s r}^{*}\right)^{c}=\left(\widetilde{\theta}_{s r}^{*}, \widetilde{\tau}_{s r}^{*}\right)$.

$X_{u}^{-}=\left(x_{s r}^{u-}\right)_{S \times R}=\left(\widetilde{\tau}_{s r}^{u-}, \widetilde{\theta}_{s r}^{u-}\right)_{S \times R}=\begin{gathered}a_{1} \\ a_{2} \\ \vdots \\ a_{S}\end{gathered}\left[\begin{array}{cccccc}\tilde{\tau}_{11}^{u-}, \widetilde{\theta}_{11}^{u-} & \widetilde{\tau}_{12}^{u-}, \widetilde{\theta}_{12}^{u-} & \cdots & \widetilde{\tau}_{1 R}^{u-}, \widetilde{\theta}_{1 R}^{u-} \\ \widetilde{\tau}_{21}^{u-}, \widetilde{\theta}_{21}^{u-} & \widetilde{\tau}_{22}^{u-}, \widetilde{\theta}_{22}^{u-} & \cdots & \widetilde{\tau}_{2 R}^{u-}, \widetilde{\theta}_{2 R}^{u-} \\ \vdots & \vdots & \vdots & \vdots \\ \tilde{\tau}_{S 1}^{u-}, \widetilde{\theta}_{S 1}^{u-} & \widetilde{\tau}_{S 2}^{u-}, \widetilde{\theta}_{S 2}^{u-} & \cdots & \widetilde{\tau}_{S R}^{u-}, \widetilde{\theta}_{S R}^{u-}\end{array}\right]_{(S \times R)}$

here $\widetilde{\tau}_{s r}^{u-}=\min _{m}\left\{\bar{\tau}_{s r}^{m}\right\}$ and $\widetilde{\theta}_{s r}^{u-}=\max _{m}\left\{\bar{\theta}_{s r}^{m}\right\} . X_{u}^{-}$is the left maximum separation from the individual positive ideal decision matrix.

$$
X_{v}^{-}=\left(x_{s r}^{v-}\right)_{S \times R}=\left(\widetilde{\tau}_{s r}^{v-}, \widetilde{\theta}_{s r}^{v-}\right)_{S \times R}=\begin{gathered}
a_{1} \\
a_{2} \\
\vdots \\
a_{S}
\end{gathered}\left[\begin{array}{cccccc}
\tilde{\tau}_{11}^{v-}, \widetilde{\theta}_{11}^{v-} & \widetilde{\tau}_{12}^{v-}, \widetilde{\theta}_{12}^{v-} & \cdots & \widetilde{\tau}_{1 R}^{v-}, \widetilde{\theta}_{1 R}^{v-} \\
\widetilde{\theta}_{21}^{v-} & \widetilde{\tau}_{22}^{v-}, \widetilde{\theta}_{22}^{v-} & . . & \widetilde{\tau}_{2 R}^{v-}, \widetilde{\theta}_{2 R}^{v-} \\
\vdots & \vdots & \vdots & \vdots \\
\tilde{\tau}_{S 1}^{v-}, \widetilde{\theta}_{S 1}^{v-} & \widetilde{\tau}_{S 2}^{v-}, \widetilde{\theta}_{S 2}^{v-} & \cdots & \widetilde{\tau}_{S R}^{v-}, \widetilde{\theta}_{S R}^{v-}
\end{array}\right]_{(S \times R)}
$$

here $\widetilde{\tau}_{s r}^{v-}=\max _{m}\left\{\bar{\tau}_{s r}^{m}\right\}$ and $\widetilde{\theta}_{s r}^{v-}=\min _{m}\left\{\bar{\theta}_{s r}^{m}\right\} \cdot X_{u}^{-}$is the right maximum separation from the individual positive ideal decision matrix.

Step 3 Hamming distance is determined in this step to analyse the properties of the ideal decision matrixes (Cheng et al. 2017). Computing the hamming distance $D_{m}^{*}$ between intuitionistic fuzzy matrix $X^{m}$ and individual positive ideal decision matrix $X^{*}$, hamming distance $D_{m}^{c}$ between $X^{m}$ and individual negative ideal decision matrix $X_{c}^{*}$, hamming distance $D_{m}^{u}$ between $X^{m}$ and left individual negative ideal decision matrix $X_{u}^{-}$and hamming distance $D_{m}^{v}$ between $X^{m}$ and right individual negative decision matrix $X_{v}^{-}$. 


$$
\begin{gathered}
D_{m}^{*}=\frac{\sum_{s=1}^{S} \sum_{r=1}^{R}\left(\left|\bar{\tau}_{s r}^{m}-\widetilde{\tau}_{s r}^{*}\right|+\left|\bar{\theta}_{s r}^{m}-\widetilde{\theta}_{s r}^{*}\right|+\left|\varphi_{s r}^{m}-\varphi_{s r}^{*}\right|\right)}{2 S R} \\
D_{m}^{c}=\frac{\sum_{s=1}^{S} \sum_{r=1}^{R}\left(\left|\bar{\tau}_{s r}^{m}-\widetilde{\theta}_{s r}^{*}\right|+\left|\bar{\theta}_{s r}^{m}-\widetilde{\tau}_{s r}^{*}\right|+\left|\varphi_{s r}^{m}-\left(\varphi_{s r}^{*}\right)^{c}\right|\right)}{2 S R} \\
D_{m}^{u}=\frac{\sum_{s=1}^{S} \sum_{r=1}^{R}\left(\left|\bar{\tau}_{s r}^{m}-\widetilde{\tau}_{s r}^{u-}\right|+\left|\bar{\theta}_{s r}^{m}-\widetilde{\theta}_{s r}^{u-}\right|+\left|\varphi_{s r}^{m}-\varphi_{s r}^{u-}\right|\right)}{2 S R} \\
D_{m}^{v}=\frac{\sum_{s=1}^{s} \sum_{r=1}^{R}\left(\left|\bar{\tau}_{s r}^{m}-\widetilde{\tau}_{s r}^{v-}\right|+\left|\bar{\theta}_{s r}^{m}-\widetilde{\theta}_{s r}^{v-}\right|+\left|\varphi_{s r}^{m}-\varphi_{s r}^{v-}\right|\right)}{2 S R}
\end{gathered}
$$

where $\quad \varphi_{s r}^{m}=1-\bar{\tau}_{s r}^{m}-\bar{\theta}_{s r}^{m}, \quad \varphi_{s r}^{*}=1-\widetilde{\tau}_{s r}^{*}-\widetilde{\theta}_{s r}^{*}, \quad\left(\varphi_{s r}^{*}\right)^{c}=1-\widetilde{\theta}_{s r}^{*}-\widetilde{\tau}_{s r}^{*}$, $\varphi_{s r}^{u-}=1-\widetilde{\tau}_{s r}^{u-}-\widetilde{\theta}_{s r}^{u-}$ and $\varphi_{s r}^{v-}=1-\widetilde{\tau}_{s r}^{v-}-\widetilde{\theta}_{s r}^{v-}$.

Step 4 Determining the relative closeness of intuitionistic fuzzy decision matrix for the alternatives, $X^{m}$ with $X^{*}, X_{c}^{*}, X_{u}^{-}$and $X_{v}^{-}$using the following relationship,

$$
C^{m}=\frac{D_{m}^{c}+D_{m}^{u}+D_{m}^{v}}{D_{m}^{*}+D_{m}^{c}+D_{m}^{u}+D_{m}^{v}}
$$

Using the value of the relative closeness, $C^{m}$ computing the weights associated with different decision makers by employing the following Eq. (24). Existed results in the literature show that the final preference order of alternatives is more accurate when the weights of Decision Makers are employed in decision making (Cheng et al. 2017).

$$
\xi^{m}=\frac{C^{m}}{\sum_{m=1}^{M} C^{m}}, \text { where } \xi^{m} \geq 0 \text { and } \sum_{m=1}^{M} \xi^{m}=0
$$

Step 5 Determining the weighted intuitionistic fuzzy decision matrix for all the decision makers in the following way,

$$
P^{m}=\xi^{m} X^{m}=\left(\sigma_{s r}^{m}, \rho_{s r}^{m}\right)_{S \times R}=\begin{gathered}
a_{1} \\
a_{2} \\
: \\
a_{S}
\end{gathered}\left[\begin{array}{ccccc}
\sigma_{11}^{m}, \rho_{11}^{m} & \sigma_{12}^{m}, \rho_{12}^{m} & . . & \sigma_{1 R}^{m}, \rho_{1 R}^{m} \\
\sigma_{21}^{m}, \rho_{21}^{m} & \sigma_{22}^{m}, \rho_{22}^{m} & . & \sigma_{2 R}^{m}, \rho_{2 R}^{m} \\
: & & : & : & : \\
\sigma_{S 1}^{m}, \rho_{S 1}^{m} & \sigma_{S 2}^{m}, \rho_{S 2}^{m} & . . & \sigma_{S R}^{m}, \rho_{S R}^{m}
\end{array}\right]_{(S \times R)}
$$

where $\sigma_{s r}^{m}$ and $\rho_{s r}^{m}$ are computed using equations, $\sigma_{s r}^{m}=1-\left(1-\bar{\tau}_{s r}^{m}\right)^{\xi^{m}}$ and $\rho_{s r}^{m}=\left(\bar{\theta}_{s r}^{m}\right)^{\xi^{m}}$. Step 6 The weighted intuitionistic fuzzy decision matrix can be represented in the following way with respect to the alternatives, 


$$
Q_{s}=\left(\sigma_{s r}^{m}, \rho_{s r}^{m}\right)_{M \times R}=\begin{gathered}
t_{1} \\
t_{2} \\
\vdots \\
t_{M}
\end{gathered}\left[\begin{array}{ccccc}
\sigma_{s 1}^{1}, \rho_{s 1}^{1} & \sigma_{s 2}^{1}, \rho_{s 2}^{1} & . . & \sigma_{s R}^{1}, \rho_{s R}^{1} \\
\sigma_{s 1}^{2}, \rho_{s 1}^{2} & \sigma_{s 2}^{2}, \rho_{s 2}^{2} & . . & \sigma_{s R}^{2}, \rho_{s R}^{2} \\
: & \vdots & : & \vdots \\
\sigma_{s 1}^{M}, \rho_{s 1}^{M} & \sigma_{s 2}^{M}, \rho_{s 2}^{M} & . . & \sigma_{s R}^{M}, \rho_{s R}^{M}
\end{array}\right]_{(M \times R)}
$$

Step 7 Using the weighted intuitionistic decision matrix to determine the positive ideal solutions, $Q^{+}$which is also referred to as the best decision matrix. Two negative ideal solutions $Q_{c}^{-}$and $Q^{-}$are also computed-the first one representing the complement of the positive ideal solution and the second one is the worst decision matrix considering all the weighted intuitionistic decision matrix with respect to the alternatives.

$$
Q^{+}=\left(\sigma_{r}^{m+}, \rho_{r}^{m+}\right)_{M \times R}=\begin{gathered}
t_{1} \\
t_{2} \\
\vdots \\
t_{M}
\end{gathered}\left[\begin{array}{cccc}
\sigma_{1}^{1+}, \rho_{1}^{1+} & \sigma_{2}^{1+}, \rho_{2}^{1+} & \cdots & \sigma_{R}^{1+}, \rho_{R}^{1+} \\
\sigma_{1}^{2+}, \rho_{1}^{2+} & \sigma_{2}^{2+}, \rho_{2}^{2+} & \cdots & \sigma_{R}^{2+}, \rho_{R}^{2+} \\
\vdots & \vdots & \vdots & \vdots \\
\sigma_{1}^{M+}, \rho_{1}^{M+} & \sigma_{2}^{M+}, \rho_{2}^{M+} & \cdots & \sigma_{R}^{M+}, \rho_{R}^{M+}
\end{array}\right]_{(M \times R)}
$$

where $\sigma_{r}^{m+}=\max _{s}\left\{\sigma_{s r}^{m}\right\}$ and $\rho_{r}^{m+}=\min _{s}\left\{\rho_{s r}^{m}\right\}$.

$$
Q_{c}^{-}=\left(\rho_{r}^{m+}, \sigma_{r}^{m+}\right)_{M \times R}=t_{2}\left[\begin{array}{ccccc}
t_{1}^{1+}, \sigma_{1}^{1+} & \rho_{2}^{1+}, \sigma_{2}^{1+} & \cdots & \rho_{R}^{1+}, \sigma_{R}^{1+} \\
\vdots & t_{M}^{2+}, \sigma_{1}^{2+} & \rho_{2}^{2+}, \sigma_{2}^{2+} & \cdots & \rho_{R}^{2+}, \sigma_{R}^{2+} \\
\vdots & \vdots & \vdots & \vdots \\
\rho_{1}^{M+}, \sigma_{1}^{M+} & \rho_{2}^{M+}, \sigma_{2}^{M+} & \cdots & \rho_{R}^{M+}, \sigma_{R}^{M+}
\end{array}\right]_{(M \times R)}
$$

$Q_{c}^{-}$is the compliment of $Q^{+}=\left(\sigma_{r}^{m+}, \rho_{r}^{m+}\right)_{M \times R}$, or $Q_{c}^{-}$can be represented as $Q_{c}^{-}=\left(\rho_{r}^{m+}, \sigma_{r}^{m+}\right)_{M \times R^{*}}$

$$
Q^{-}=\left(\sigma_{r}^{m-}, \rho_{r}^{m-}\right)_{M \times R}=\begin{gathered}
t_{1} \\
t_{2} \\
\vdots \\
t_{M}
\end{gathered}\left[\begin{array}{cccc}
\sigma_{1}^{1-}, \rho_{1}^{1-} & \sigma_{2}^{1-}, \rho_{2}^{1-} & \cdots & \sigma_{R}^{1-}, \rho_{R}^{1-} \\
\sigma_{1}^{2-}, \rho_{1}^{2-} & \sigma_{2}^{2-}, \rho_{2}^{2-} & \cdots & \sigma_{R}^{2-}, \rho_{R}^{2-} \\
\vdots & \vdots & \vdots & \vdots \\
\sigma_{1}^{M-}, \rho_{1}^{M-} & \sigma_{2}^{M-}, \rho_{2}^{M-} & \cdots & \sigma_{R}^{M-}, \rho_{R}^{M-}
\end{array}\right]_{(M \times R)}
$$

here $\sigma_{r}^{m-}=\min _{s}\left\{\sigma_{s r}^{m}\right\}$ and $\rho_{r}^{m-}=\max _{s}\left\{\rho_{s r}^{m}\right\}$.

Step 8 Determining the separation of the weight intuitionistic decision matrix $Q_{s}$ from the positive ideal solution $Q^{+}$and two negative ideal solutions $Q_{c}^{-}$and $Q^{-} . D_{s}^{+}, D_{s}^{c}$ and $D_{s}^{-}$represents the separation of $Q_{s}$ from $Q^{+}, Q_{c}^{-}$and $Q^{-}$respectively and it can be computed in the following way,

$$
\begin{gathered}
D_{s}^{+}=\frac{\sum_{r=1}^{R} \sum_{m=1}^{M}\left(\left|\sigma_{s r}^{m}-\sigma_{r}^{m+}\right|+\left|\rho_{s r}^{m}-\rho_{r}^{m+}\right|+\left|\varepsilon_{s r}^{m}-\varepsilon_{r}^{m+}\right|\right)}{2 R M} \\
D_{s}^{c}=\frac{\sum_{r=1}^{R} \sum_{m=1}^{M}\left(\left|\sigma_{s r}^{m}-\rho_{r}^{m+}\right|+\left|\rho_{s r}^{m}-\sigma_{r}^{m+}\right|+\left|\varepsilon_{s r}^{m}-\left(\varepsilon_{r}^{m+}\right)^{c}\right|\right)}{2 R M}
\end{gathered}
$$




$$
D_{s}^{-}=\frac{\sum_{r=1}^{R} \sum_{m=1}^{M}\left(\left|\sigma_{s r}^{m}-\sigma_{r}^{m-}\right|+\left|\rho_{s r}^{m}-\rho_{r}^{m-}\right|+\left|\varepsilon_{s r}^{m}-\varepsilon_{r}^{m-}\right|\right)}{2 R M}
$$

here $\quad \varepsilon_{s r}^{m}=1-\sigma_{s r}^{m}-\rho_{s r}^{m}, \quad \varepsilon_{r}^{m+}=1-\sigma_{r}^{m+}-\rho_{r}^{m+}, \quad\left(\varepsilon_{r}^{m+}\right)^{c}=1-\rho_{r}^{m+}-\sigma_{r}^{m+} \quad$ and $\varepsilon_{r}^{m-}=1-\sigma_{r}^{m-}-\rho_{r}^{m-}$.

Step 9 Determining the relative closeness for each alternative using the following equation,

$$
C^{s}=\frac{D_{s}^{c}+D_{s}^{-}}{D_{s}^{+}+D_{s}^{c}+D_{s}^{-}}
$$

Alternative, $a_{1}$ is better than $a_{2}$ only if $C^{a_{1}}$ is greater than $C^{a_{2}}$.

\section{Application of methodologies and results obtained}

In this section, the results obtained by using intuitionistic fuzzy AHP for determining the rank of the KPIs are presented. In the first sub-section, a numerical illustration associated with KPIs related to environmental combined with strategic is presented. This presentation illustrates the application of intuitionistic fuzzy AHP. The second sub-section presents the ranking provided by VFT for the KPIs under different categories obtained by classifying the KPIs into environmental, social and economic criteria. This sub-section also presents the intuitionistic fuzzy weight obtained for each of the KPIs and the importance of every KPI. The third sub-section presents a case study, which aims to determine the performance of the various organisation and provides appropriate suggestions regarding the KPIs which require necessary improvement. The last sub-section presents the application of IF-TOPSIS to rank all the organisations based on their performance on different KPIs.

\subsection{A case application}

In order to determine the relative importance of KPIs and their respective weights, a panel of three experts were asked to give their opinion. The experts have more than 15 years of working experience in senior supply chain roles within the organisations in the UK. A pair wise comparison is carried out by the experts using linguistic term. These comparisons are then transformed into intuitionistic fuzzy values and used as input to the IFAHP method for the computation of KPIs weights. The decision-maker provides his/her preference information for the KPIs related to environmental combined with strategic - innovation \& improvement, planning and product design, compliance to regulations, environmental quality management, management commitment and governmental regulations. Thus, $v$ is the intuitionistic preference relation obtained from the decision-maker.

$$
\begin{aligned}
v & =\left(v_{p q}\right)_{m \times m}=\left(\alpha_{p q}, \beta_{p q}\right)_{m \times m} \\
& =\left[\begin{array}{llllll}
(0.5,0.5) & (0.2,0.6) & (0.3,0.9) & (0.4,0.7) & (0.8,0.3) & (0.2,0.8) \\
(0.6,0.2) & (0.5,0.5) & (0.6,0.1) & (0.3,0.5) & (0.7,0.4) & (0.8,0.3) \\
(0.9,0.3) & (0.1,0.6) & (0.5,0.5) & (0.9,0.2) & (0.3,0.6) & (0.8,0.4) \\
(0.7,0.4) & (0.5,0.3) & (0.2,0.9) & (0.5,0.5) & (0.2,0.7) & (0.6,0.2) \\
(0.3,0.8) & (0.4,0.7) & (0.6,0.3) & (0.7,0.2) & (0.5,0.5) & (0.8,0.1) \\
(0.8,0.2) & (0.3,0.8) & (0.4,0.8) & (0.2,0.6) & (0.8,0.1) & (0.5,0.5)
\end{array}\right]
\end{aligned}
$$


From step 1 of the procedure of IFAHP, the intuitionistic preference relation for all the criteria is obtained from the decision-maker. Now, determining the perfect multiplicative consistent intuitionistic preference relation using Eqs. (7) and (8) given in step 2.

$$
\begin{aligned}
\bar{v} & =\left(\bar{v}_{p q}\right)_{m \times m}=\left(\bar{\alpha}_{p q}, \bar{\beta}_{p q}\right)_{m \times m} \\
& =\left[\begin{array}{cccccc}
(0.5,0.5) & (0.2,0.6) & (0.27,0.14) & (0.39,0.64) & (0.20,0.80) & (0.69,0.36) \\
(0.6,0.2) & (0.5,0.5) & (0.6,0.1) & (0.93,0.02) & (0.20,0.38) & (0.76,0.1) \\
(0.14,0.27) & (0.1,0.6) & (0.5,0.5) & (0.9,0.2) & (0.69,0.36) & (0.82,0.09) \\
(0.64,0.39) & (0.02,0.93) & (0.2,0.9) & (0.5,0.5) & (0.2,0.7) & (0.5,0.20) \\
(0.80,0.20) & (0.38,0.20) & (0.36,0.69) & (0.7,0.2) & (0.5,0.5) & (0.8,0.1) \\
(0.36,0.69) & (0.1,0.76) & (0.09,0.82) & (0.20,0.5) & (0.1,0.8) & (0.5,0.5)
\end{array}\right]
\end{aligned}
$$

Now according to step 3, computing the distance measure between the intuitionistic preference relation $v=\left(v_{p q}\right)_{m \times m}$ and perfect multiplicative consistent intuitionistic preference relation $\bar{v}=\left(\bar{v}_{p q}\right)_{m \times m}, \operatorname{Dist}(\bar{v}, v)=0.4105$. In step 4 , the distance measure is compared with the consistency threshold $\lambda$ (assuming the value of $\lambda$ as 0.1 as given in $\mathrm{Xu}$ and Liao (2014). As, Dist $(\bar{v}, v)=0.4105>\lambda(=0.1)$, therefore move on to step 5 for computing the fused intuitionistic preference relation $\widetilde{s}$.

$$
\begin{aligned}
\tilde{s} & =\left(\tilde{s}_{p q}\right)_{m \times m}=\left(\tilde{x}_{p q}, \tilde{z}_{p q}\right) \\
& =\left[\begin{array}{cccccc}
(0.5,0.5) & (0.2,0.6) & (0.27,0.27) & (0.39,0.65) & (0.31,0.72) & (0.59,0.45) \\
(0.6,0.2) & (0.5,0.5) & (0.6,0.1) & (0.87,0.05) & (0.28,0.38) & (0.77,0.12) \\
(0.27,0.27) & (0.1,0.6) & (0.5,0.5) & (0.9,0.2) & (0.61,0.41) & (0.82,0.12) \\
(0.65,0.39) & (0.05,0.87) & (0.2,0.9) & (0.5,0.5) & (0.2,0.7) & (0.52,0.20) \\
(0.72,0.31) & (0.38,0.28) & (0.41,0.61) & (0.7,0.2) & (0.5,0.5) & (0.8,0.1) \\
(0.45,0.59) & (0.12,0.77) & (0.12,0.82) & (0.20,0.52) & (0.1,0.8) & (0.5,0.5)
\end{array}\right]
\end{aligned}
$$

Now the distance measure between the fused intuitionistic preference relation and perfect multiplicative consistent intuitionistic preference relation is computed as given in step 6. So, the distance measure is, Dist $(\bar{v}, \widetilde{s})=0.065$ which is compared with the consistency threshold $\lambda$ in step 4 and found that the distance measure is less than $\lambda$ or $\operatorname{Dist}(\bar{v}, \widetilde{s})=0.065<\lambda(=0.1)$. Now, the fused intuitionistic preference relation $\widetilde{s}$ is obtained as the output and using Eq. (12) given in step 7, the intuitionistic fuzzy weight for each of the KPIs is obtained. Intuitionistic fuzzy weights are given as follows, $K P I_{(\text {Innovation \& improvement) }}=(0.11,0.82)$, $K P I_{(\text {Planning and product design })}=(0.18,0.71), \quad K P I_{(\text {Compliance to regulations })}=(0.16,0.76)$, $K P I_{(\text {Environment quality management })}=(0.10,0.85), \quad K P I_{(\text {Management commitment })}=(0.17,0.75) \quad$ and $K P I_{(\text {Government regulations })}=(0.07,0.87)$. The next section provides the results obtained using IFAHP for all the KPIs and also presents the case study for validating the performance of the organizations. 


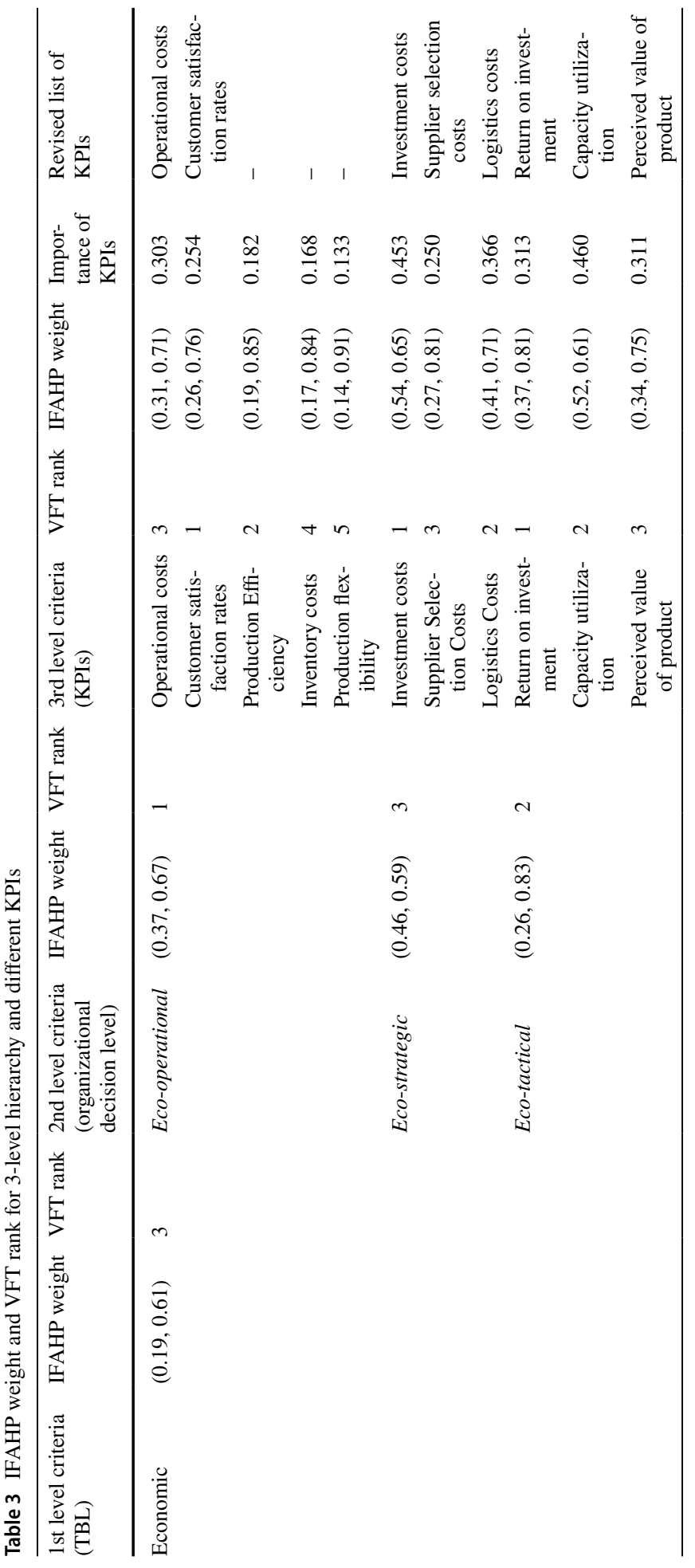




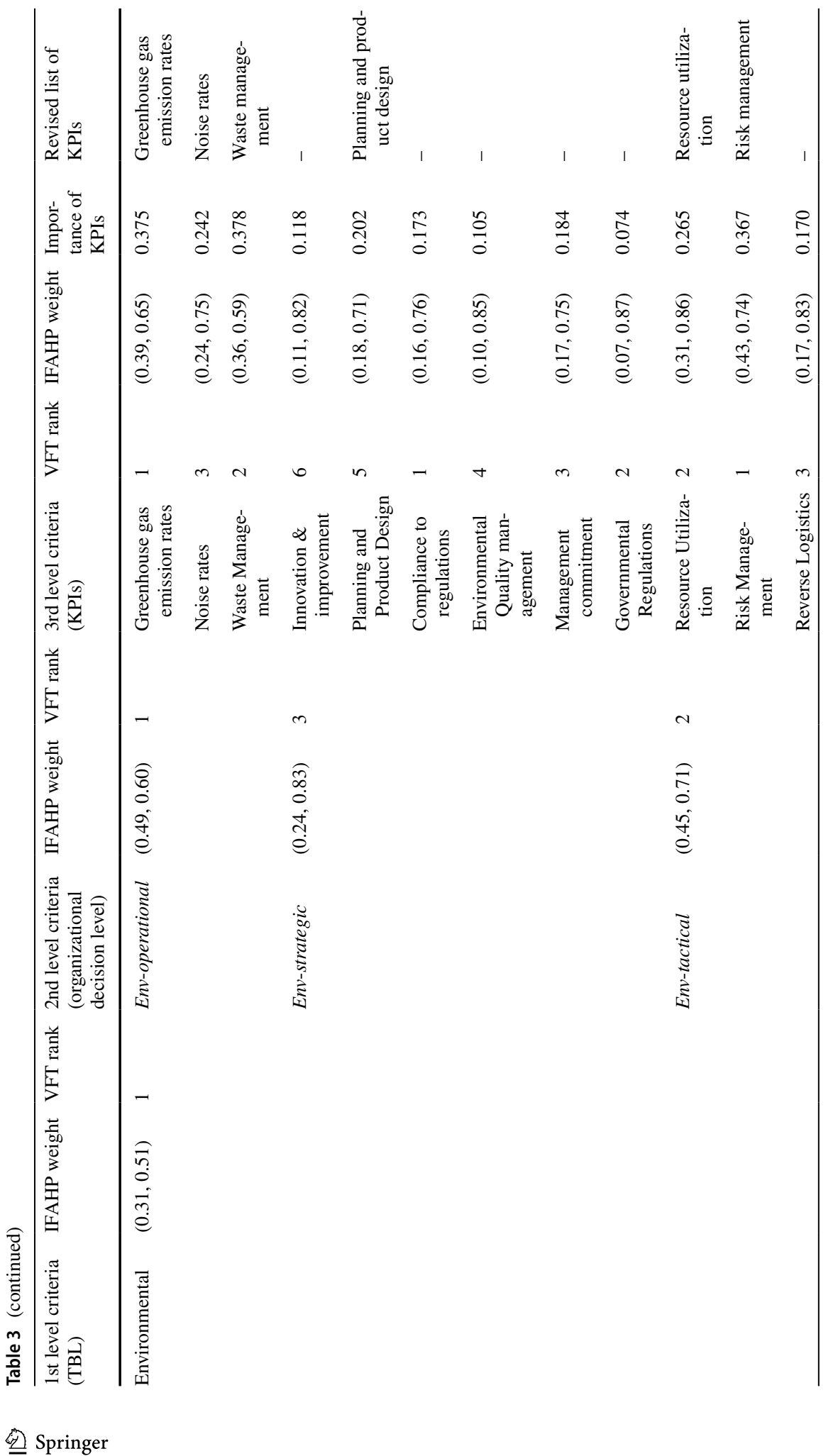




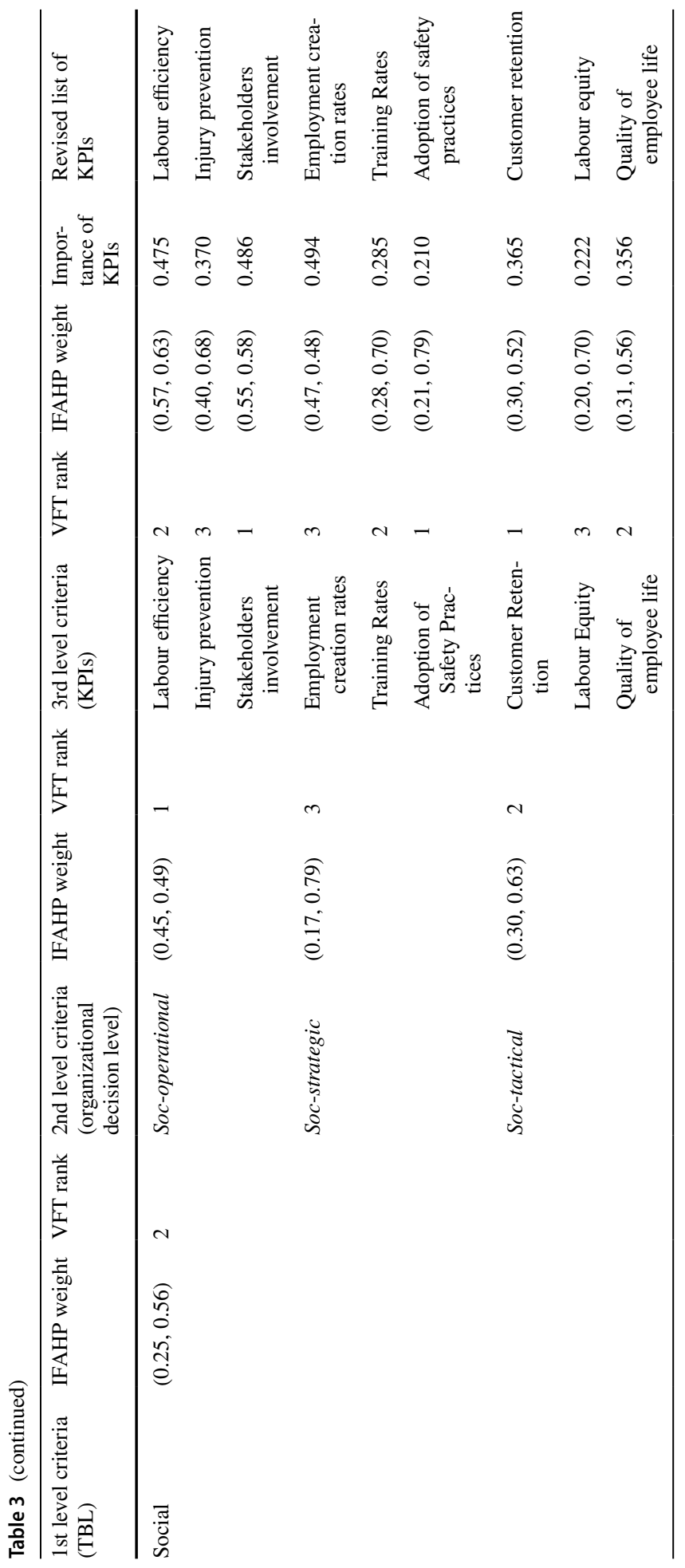




\subsection{Results obtained using VFT and IFAHP}

The results obtained from the VFT approach is presented in Table 3 and it can be assessed from Table 3 that the most important VFT choices of the experts are customer retention, rate of adoption of safety practices, stakeholders involvement, risk management, compliance with regulations, investment costs, greenhouse gas (GHG) emission rates, return on investments and customer satisfaction rates. It is evident from the above list that an organisation's customers, stakeholders and financial standing are all perceived to have the highest values of importance for the implementation of sustainability within organisations. Although, it is essential to compare the result obtained using VFT with that of intuitionistic Fuzzy analytic hierarchy process for dealing with the ambiguity and complexity of the decision making process. Table 3 presents the IFAHP weight and VFT ranking for three different levels. From the Table 3, the following KPIs are identified as the most important as per the VFT choices of experts; Customer Retention, Rate of Adoption of Safety Practices, Stakeholders Involvement, Risk Management, Compliance to Regulations, Investment Costs, Greenhouse Gas (GHG) Emission Rate, Return on Investments, Customer Satisfaction Rates. The perceived importance as per the VFT is Environmental KPIs $>$ Social KPIs $>$ Economic KPIs. Table 3 also provides the importance associated with each of the KPIs. The following equation given by Tooranloo and sadat Ayatollah (2016) is used to estimate the importance of each KPI.

$$
\omega_{n}=\left(\frac{\alpha_{n}+\eta_{n}\left(\frac{\alpha_{n}}{\alpha_{n}+\beta_{n}}\right)}{\sum_{n=1}^{N}\left(\alpha_{n}+\eta_{n}\left(\frac{\alpha_{n}}{\alpha_{n}+\beta_{n}}\right)\right)}\right) \text {, where } \sum_{n=1}^{N} \omega_{n}=1
$$

here $n$ represents the KPI and total number of KPIs is given by $N . \omega_{n}$ is the importance given to each KPI $n$. Intuitionistic fuzzy weight obtained for each KPI can be represented in the following way, $w_{n}=\left(\alpha_{n}, \beta_{n}\right)$. Here, $\alpha_{n}$ is the degree of the membership and $\beta_{n}$ is the degree of non-membership. Using the values of $\alpha_{n}$ and $\beta_{n}$, the degree of hesitancy can be computed or $\eta_{n}=1-\alpha_{n}-\beta_{n}$. So, employing the Eq. (13), the importance associated with the KPIs is determined and presented in Table 3. However, it is noteworthy that the list of KPIs is quite a large list, which could be problematic for the further incorporation within the subsequent stages and hence, it is imperative for the list to be reduced to a more practical quantity. Therefore, KPI with less than 0.20 importance is omitted and the rest of the KPIs having more than 0.20 values are considered for the case study.

Table 3 provides a detailed information about the intuitionistic fuzzy weights obtained for each of the KPIs using intuitionistic fuzzy AHP. The importance of each KPI is obtained from the intuitionistic fuzzy weight using Eq. (3) provided by Tooranloo and sadat Ayatollah (2016). Moreover, Table 4 also presents the importance of each KPIs, which are used to determine the revised list of KPIs after comparing with the threshold limit of 0.20 . Figure 3 presents the importance of all the KPIs and compares it with the threshold limit of 0.20. Moreover, it gives a visual illustration of the comparative importance of the KPIs. 
Table 4 Performance ratings for different KPIs obtained for different organizations

\begin{tabular}{|c|c|c|c|c|c|c|c|c|}
\hline \multirow[t]{2}{*}{ S. no. } & \multirow[t]{2}{*}{ KPI } & \multicolumn{6}{|c|}{ Organization } & \multirow[t]{2}{*}{ Average } \\
\hline & & A & B & $\mathrm{C}$ & $\mathrm{D}$ & E & $\mathrm{F}$ & \\
\hline 1 & Customer satisfaction rates & 4 & 3 & 3 & 4 & 4 & 2 & 3.33 \\
\hline 2 & Operational costs & 3 & 4 & 5 & 3 & 2 & 4 & 3.50 \\
\hline 3 & Investment cost & 4 & 4 & 4 & 2 & 1 & 3 & 3.00 \\
\hline 4 & Return on investment & 4 & 3 & 5 & 1 & 2 & 3 & 3.00 \\
\hline 5 & GHG emission rates & 3 & 1 & 4 & 2 & 2 & 4 & 2.66 \\
\hline 6 & Logistic cost & 2 & 2 & 3 & 3 & 4 & 2 & 2.66 \\
\hline 7 & Supplier selection costs & 5 & 4 & 3 & 5 & 1 & 5 & 3.83 \\
\hline 8 & Perceived value of product & 4 & 3 & 1 & 4 & 5 & 2 & 3.16 \\
\hline 9 & Noise rates & 3 & 2 & 5 & 5 & 3 & 4 & 3.66 \\
\hline 10 & Planning and product design & 1 & 5 & 2 & 2 & 2 & 3 & 2.50 \\
\hline 11 & Stakeholders involvement & 3 & 2 & 4 & 1 & 4 & 2 & 2.66 \\
\hline 12 & Employment creation rates & 2 & 2 & 4 & 3 & 2 & 4 & 2.83 \\
\hline 13 & Capacity utilisation & 2 & 3 & 3 & 4 & 4 & 3 & 3.16 \\
\hline 14 & Labour efficiency & 3 & 5 & 3 & 3 & 4 & 4 & 3.66 \\
\hline 15 & Waste management & 4 & 2 & 2 & 2 & 3 & 1 & 2.33 \\
\hline 16 & Injury prevention & 5 & 3 & 2 & 3 & 5 & 2 & 3.33 \\
\hline 17 & Resource utilization & 3 & 3 & 4 & 3 & 2 & 3 & 3.00 \\
\hline 18 & Training rates & 4 & 1 & 2 & 1 & 4 & 4 & 2.66 \\
\hline 19 & Risk management & 3 & 2 & 4 & 3 & 3 & 4 & 3.16 \\
\hline 20 & Adoption of safety practices & 4 & 4 & 3 & 3 & 4 & 2 & 3.33 \\
\hline 21 & Customer retention & 5 & 3 & 4 & 4 & 4 & 2 & 3.66 \\
\hline 22 & Labour equity & 4 & 3 & 2 & 2 & 1 & 1 & 2.16 \\
\hline 23 & Quality of employee life & 3 & 4 & 3 & 2 & 4 & 2 & 3.00 \\
\hline Total score & & 78 & 68 & 75 & 65 & 70 & 66 & \\
\hline Mean score & & 3.391 & 2.956 & 3.260 & 2.826 & 3.043 & 2.869 & \\
\hline
\end{tabular}

\subsection{A case study}

The sustainability performance of various organisations can be judged based on the most influential KPIs and their respective importance. Depending on the initial results of importance presented in $r$, the identified KPIs can be used for the computational purpose; wherein each organisation can identify which Key Performance Indicators (KPIs) need to be focused on to further assess, manage and improve these KPIs. Among all the research methodologies identified across the supply chain and sustainability research domains, a case study approach was deemed most appropriate due to its structured approach and indepth analysis. For the case study purpose, performance ratings related to selected list of KPIs are obtained from six manufacturing organisations of UK origin operating in different part of United Kingdom. For confidentiality purposes, the organisations have requested to remain anonymous for this research. A panel of three experts from each organisation is selected to rate the sustainability performance of the organisations based on the KPIs identified using IFAHP method. Table 4 presents the consolidated performance ratings of six organisations provided by the experts based on the scale of 1 to 5 , where 1 is poor 


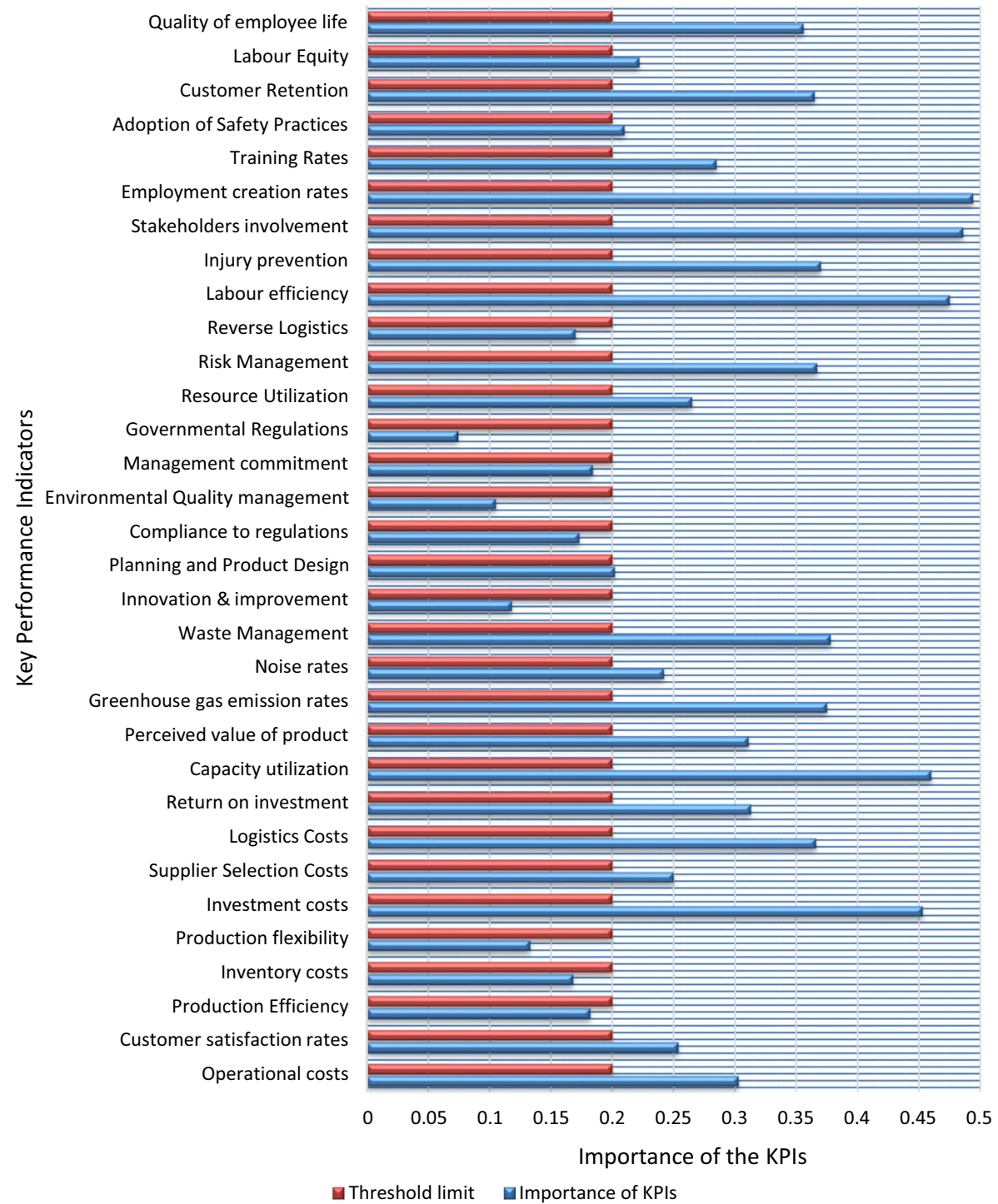

Fig. 3 Importance of the KPIs and the threshold limit

performance, and 5 is an excellent performance. This reflects the performance of each organisation with respect to each of the KPIs. However, this method does not provide an overall ranking of each organisation to evaluate their relative sustainability performance.

The importance of the KPI given in Table 3 and the performance rating of each organization for every KPI are considered for determining the overall performance of the organization. For a certain KPI, the performance rating of 1, 2, 3, 4 or 5 ensures a rating score of $0.2,0.4,0.6,0.8$ and 1 respectively. Figure 4 presents the pseudo-code of the logic employed for determining the performance score of the organization and also provides the information regarding the performance of the KPIs in the organization. The importance 
Fig. 4 Pseudo-code for determining the performance of the organization based on the importance of the KPIs
Procedure: Determining the organization's performance 1. Store the rating of each KPI of the organization in $A$

2. Store the importance value of each KPI in K

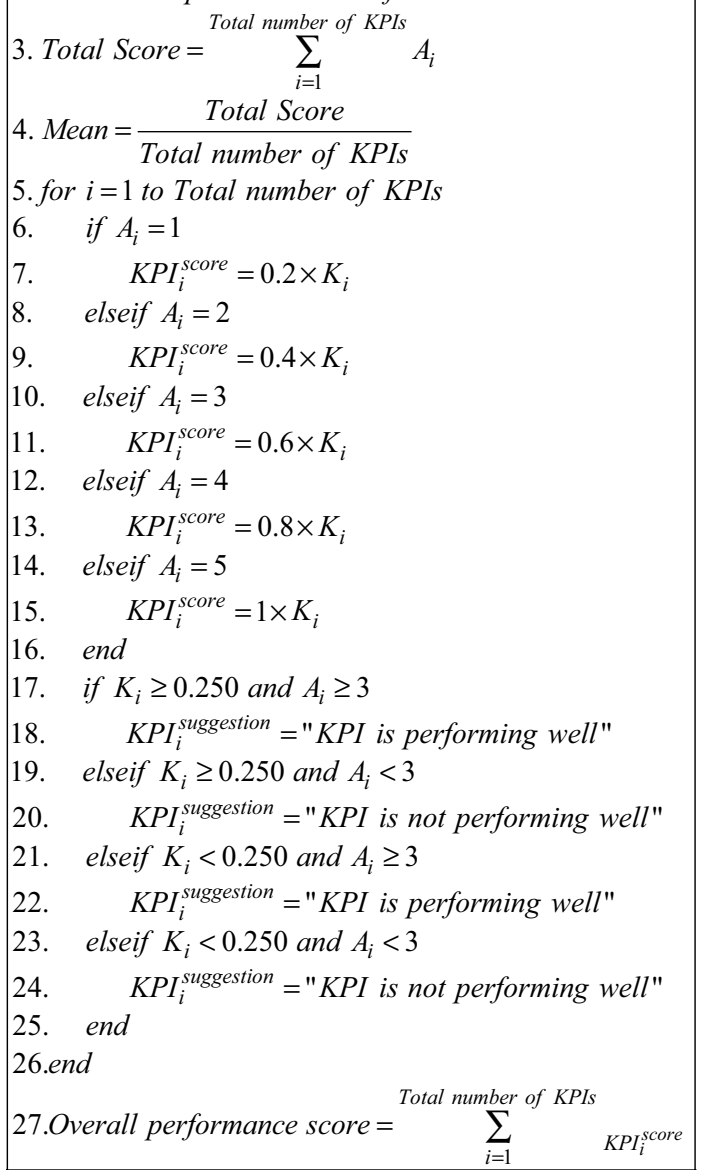

values of the KPIs are utilized to identify the KPIs performing well for the organization. For organization A, the overall performance score is 5.215 and the organization needs to pay further attention of the following KPIs-logistic cost, planning and product design, employment creation rates and capacity utilisation. The performance score of organization B is 4.535 and some of the KPIs which need thorough improvement are GHG emission rates, logistic cost, noise rates, stakeholder's involvement, employment creation rates, waste management, training rates and risk management. Pseudo-code presented in Fig. 4 helps in computing the performance score for the organizations and also provides recommendation regarding which KPI requires improvement.

It is apparent from Table 5 that some of the KPIs such as customer satisfaction rates, operational cost, supplier selection costs, noise rates, labour efficiency, injury prevention, adoption of safety practices and customer retention are given high preference by most of the organisations. Certain KPIs have a high degree of variations regarding preference within different organisations such as return on investment and perceived value of the product. The development of the methodology and its pilot-testing with the organisations 
Table 5 Organization performance score

\begin{tabular}{|c|c|c|c|c|c|c|c|c|}
\hline \multirow[t]{2}{*}{ S. no. } & \multirow[t]{2}{*}{ KPI } & \multirow[t]{2}{*}{ Importance } & \multicolumn{6}{|c|}{ Organizations (Org.) performance scores } \\
\hline & & & Org. A & Org. B & Org. C & Org. D & Org. E & Org. $\mathrm{F}$ \\
\hline 1 & Customer satisfaction rates & 0.254 & 0.203 & 0.152 & 0.152 & 0.203 & 0.203 & 0.101 \\
\hline 2 & Operational costs & 0.303 & 0.181 & 0.242 & 0.303 & 0.181 & 0.121 & 0.242 \\
\hline 3 & Investment cost & 0.453 & 0.362 & 0.362 & 0.364 & 0.181 & 0.090 & 0.271 \\
\hline 4 & Return on investment & 0.313 & 0.250 & 0.187 & 0.313 & 0.062 & 0.125 & 0.187 \\
\hline 5 & GHG emission rates & 0.375 & 0.225 & 0.075 & 0.300 & 0.150 & 0.150 & 0.300 \\
\hline 6 & Logistic cost & 0.366 & 0.146 & 0.146 & 0.219 & 0.219 & 0.292 & 0.146 \\
\hline 7 & Supplier selection costs & 0.250 & 0.250 & 0.200 & 0.150 & 0.250 & 0.050 & 0.250 \\
\hline 8 & Perceived value of product & 0.311 & 0.248 & 0.186 & 0.062 & 0.248 & 0.311 & 0.124 \\
\hline 9 & Noise rates & 0.242 & 0.145 & 0.096 & 0.242 & 0.242 & 0.145 & 0.193 \\
\hline 10 & $\begin{array}{l}\text { Planning and product } \\
\text { design }\end{array}$ & 0.202 & 0.040 & 0.202 & 0.080 & 0.080 & 0.080 & 0.121 \\
\hline 11 & Stakeholders involvement & 0.486 & 0.291 & 0.194 & 0.388 & 0.097 & 0.388 & 0.194 \\
\hline 12 & Employment creation rates & 0.494 & 0.197 & 0.197 & 0.395 & 0.296 & 0.197 & 0.395 \\
\hline 13 & Capacity utilisation & 0.460 & 0.184 & 0.276 & 0.276 & 0.368 & 0.368 & 0.276 \\
\hline 14 & Labour efficiency & 0.475 & 0.285 & 0.475 & 0.285 & 0.285 & 0.380 & 0.380 \\
\hline 15 & Waste management & 0.378 & 0.302 & 0.151 & 0.151 & 0.151 & 0.226 & 0.075 \\
\hline 16 & Injury prevention & 0.370 & 0.370 & 0.222 & 0.148 & 0.222 & 0.370 & 0.148 \\
\hline 17 & Resource utilization & 0.265 & 0.159 & 0.159 & 0.212 & 0.159 & 0.106 & 0.159 \\
\hline 18 & Training rates & 0.285 & 0.228 & 0.057 & 0.114 & 0.057 & 0.228 & 0.228 \\
\hline 19 & Risk management & 0.367 & 0.220 & 0.146 & 0.293 & 0.220 & 0.220 & 0.293 \\
\hline 20 & Adoption of safety practices & 0.210 & 0.168 & 0.168 & 0.126 & 0.126 & 0.168 & 0.084 \\
\hline 21 & Customer retention & 0.365 & 0.365 & 0.219 & 0.292 & 0.292 & 0.292 & 0.146 \\
\hline 22 & Labour equity & 0.222 & 0.177 & 0.133 & 0.088 & 0.088 & 0.044 & 0.044 \\
\hline 23 & Quality of employee life & 0.356 & 0.213 & 0.284 & 0.213 & 0.142 & 0.284 & 0.142 \\
\hline Total score & & & 5.215 & 4.535 & 5.169 & 4.325 & 4.844 & 4.505 \\
\hline
\end{tabular}

facilitates the identification of the key organisational KPIs, which play a significant role in the implementation of SSCM. Furthermore, this knowledge could act as a foundation for further developing policies which could facilitate and drive the implementation of SSCM. As can be seen in Fig. 5, there is a range of different performance levels across the KPIs, and it is quite visible that organisational performance across the different KPIs varies significantly. Customer Retention, labour efficiency and logistic cost have a high degree of variance between the organisations. This could be due to the various priorities of each of the organisation such as certain organisations gives more priority in retaining its customer and thereby gives more values to customer feedback and customer services, and some of the organisations give less priority to customer retention. Organisational performance on resource utilisation, risk management, GHG emission and waste management have a low threshold across the different organisations. These points need further critical analysis and evaluation for enhancing the performance of the organisation. It is also interesting to note that stakeholder's involvement and employment creation rates have moderate to high-performance levels across the organisations. 

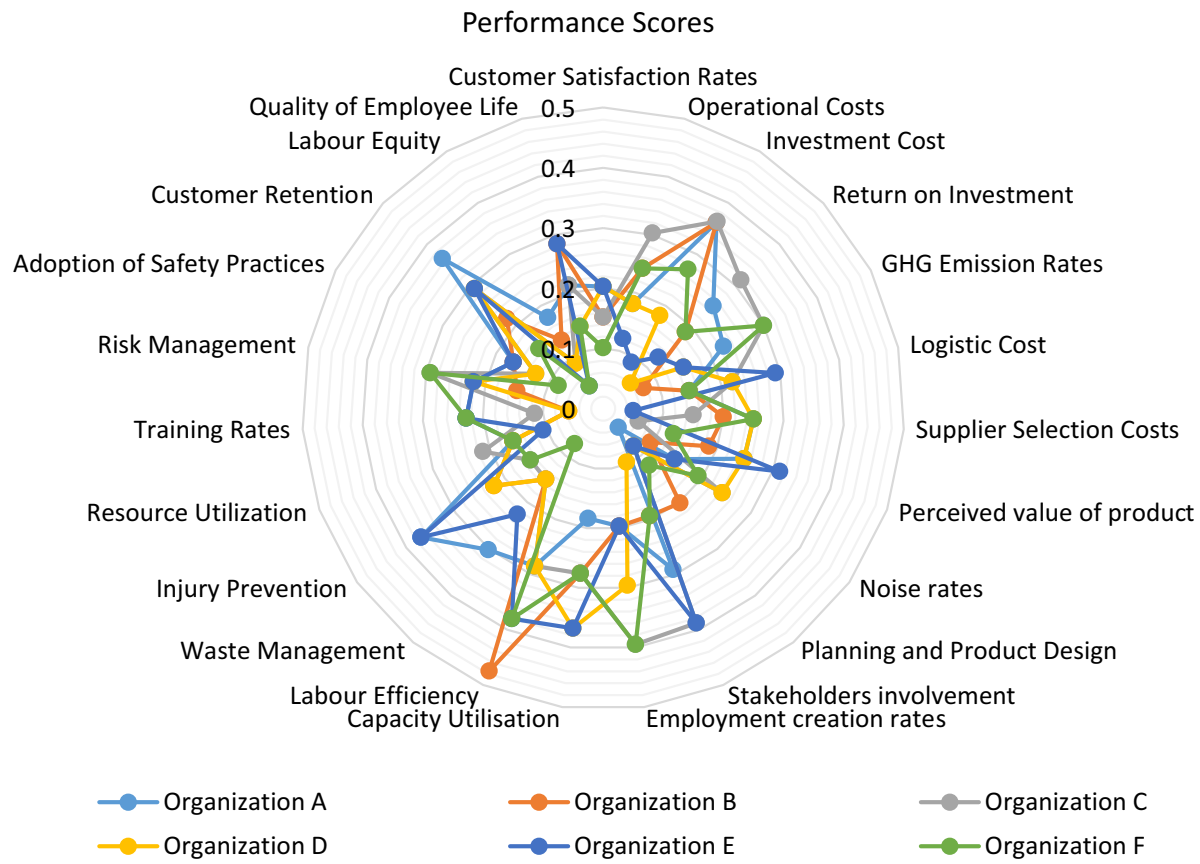

Fig. 5 Radar diagram of performance scores of six organisations on different KPIs

\subsection{Application of intuitionistic fuzzy TOPSIS}

The same panel of three experts is asked to provide their opinion on the performance of the organizations based on linguistic terms. These terms are then transformed into intuitionistic fuzzy data and then used by IF-TOPSIS system to determine the ranking of organizations based on their sustainability performance. Three decision makers provided their respective intuitionistic fuzzy data for the evaluation of different organizations with respect to various KPIs. The linguistic preference relation for each of the decision makers 1,2 and 3 are presented in Table $6(\mathrm{a}-\mathrm{c})$ respectively. The weighted intuitionistic preference matrix $X^{m}$ for all the decision makers is obtained by multiplying with the normalized weight for respective KPIs. Table 7 presents the crisp weight of each KPI and also the weighted intuitionistic preference relation for decision maker 1 . The crisp weight presented in Table 7 is obtained by normalizing the importance value of all the KPIs. The weighted intuitionistic preference relation for each of the decision maker is computed using the Eq. (14). The positive ideal solution matrix $X^{*}$, negative ideal decision matrix $X_{c}^{*}$, left individual negative ideal decision matrix $X_{u}^{-}$and right individual negative ideal decision matrix $X_{v}^{-}$are constructed using Eqs. (15), (16), (17) and (18). The hamming distances with respect to positive and negative ideal decision matrices $D_{m}^{*}, D_{m}^{c}, D_{m}^{u}$ and $D_{m}^{v}$ are estimated from the Eqs. (19), (20), (21) and (22). The relative closeness of each decision maker $C^{m}$ and its respective weight $\xi^{m}$ are computed using Eqs. (23) and (24) and their value are presented in Table 8.

The weighted intuitionistic fuzzy decision matrix $P^{m}$ for all the decision makers are obtained using Eq. (25) where the decision makers weight $\xi^{m}$ is multiplied with the respective decision matrix $X^{m}$. Now, the weighted intuitionistic fuzzy decision matrix with 


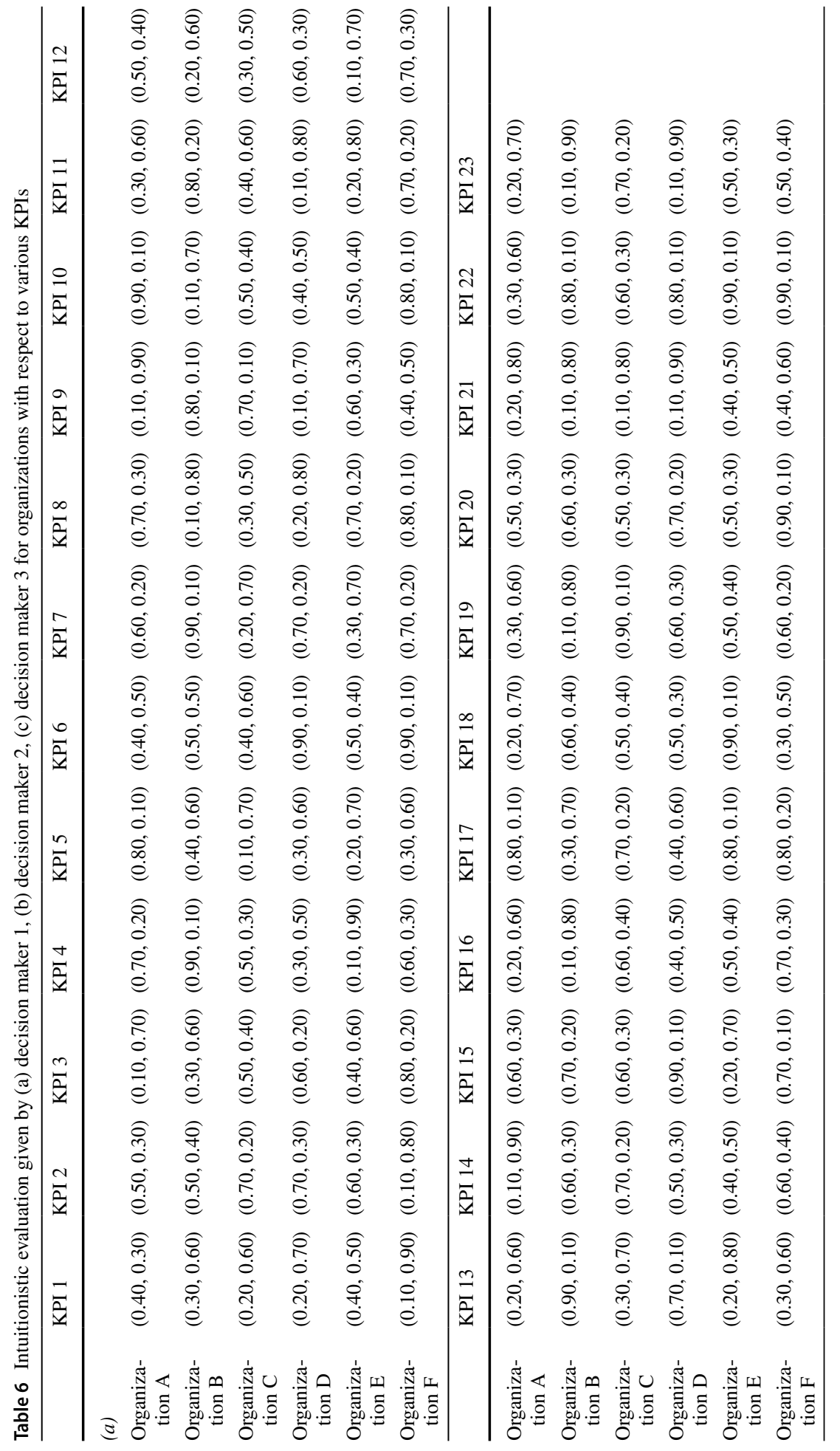




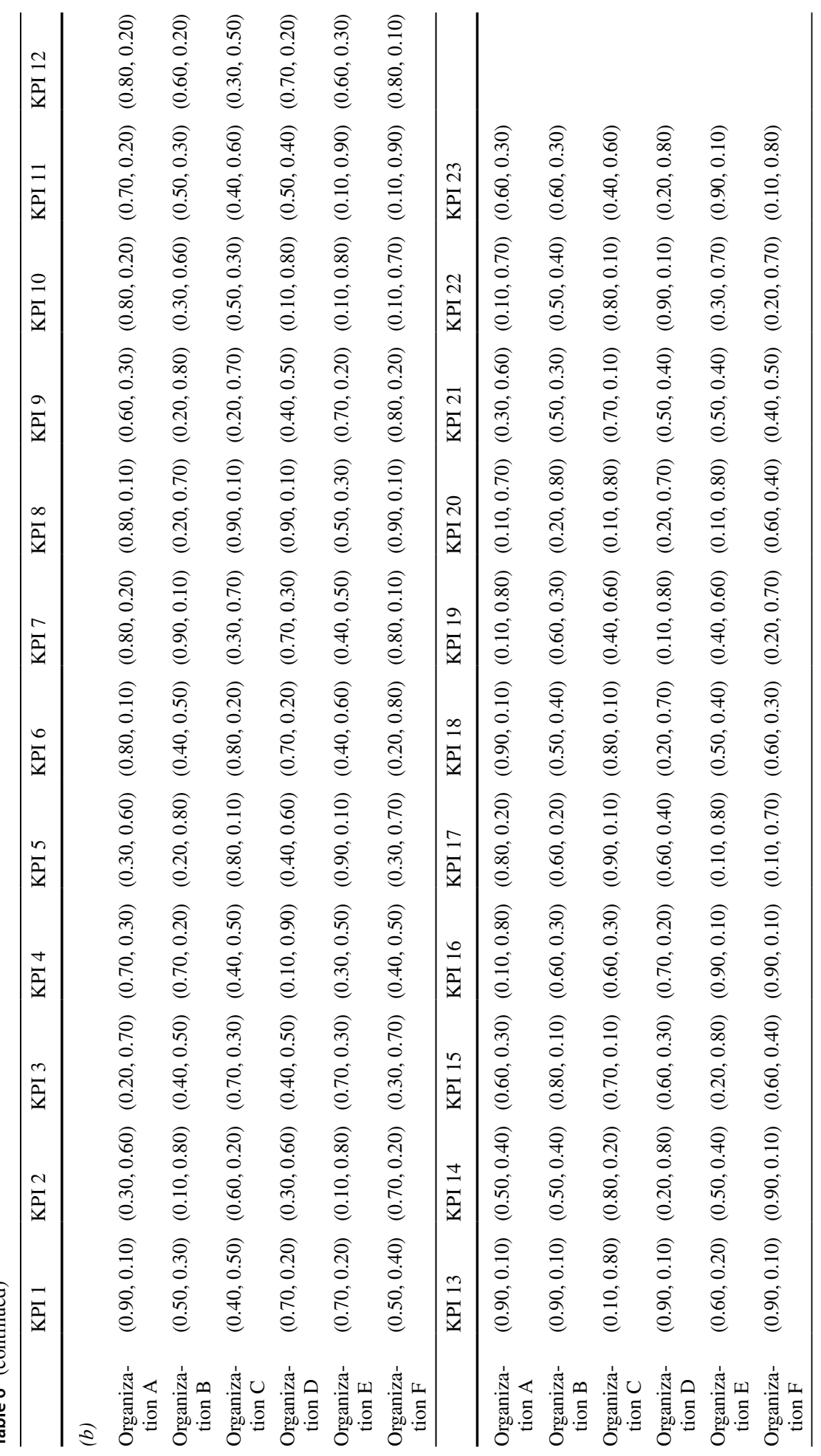




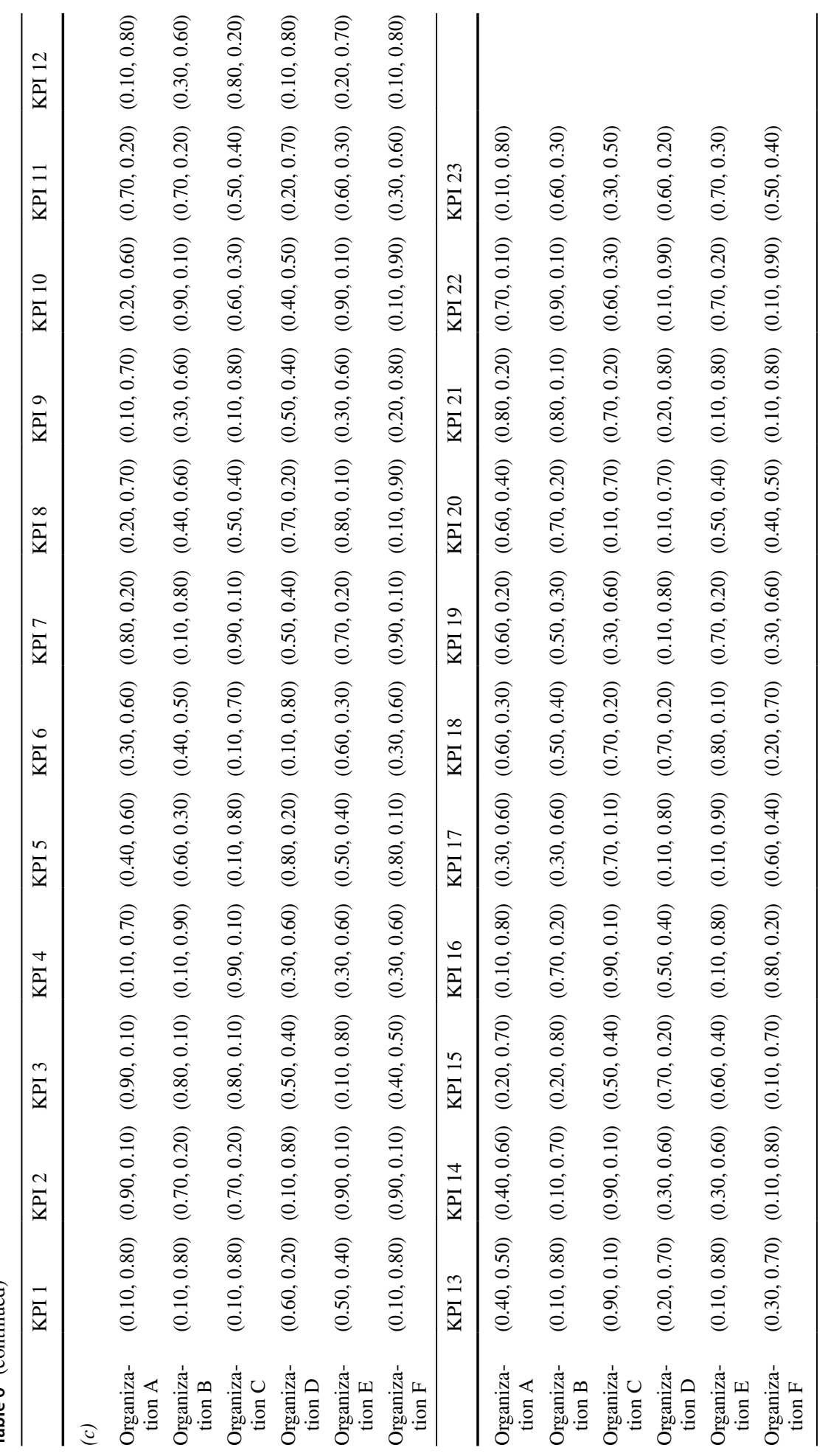




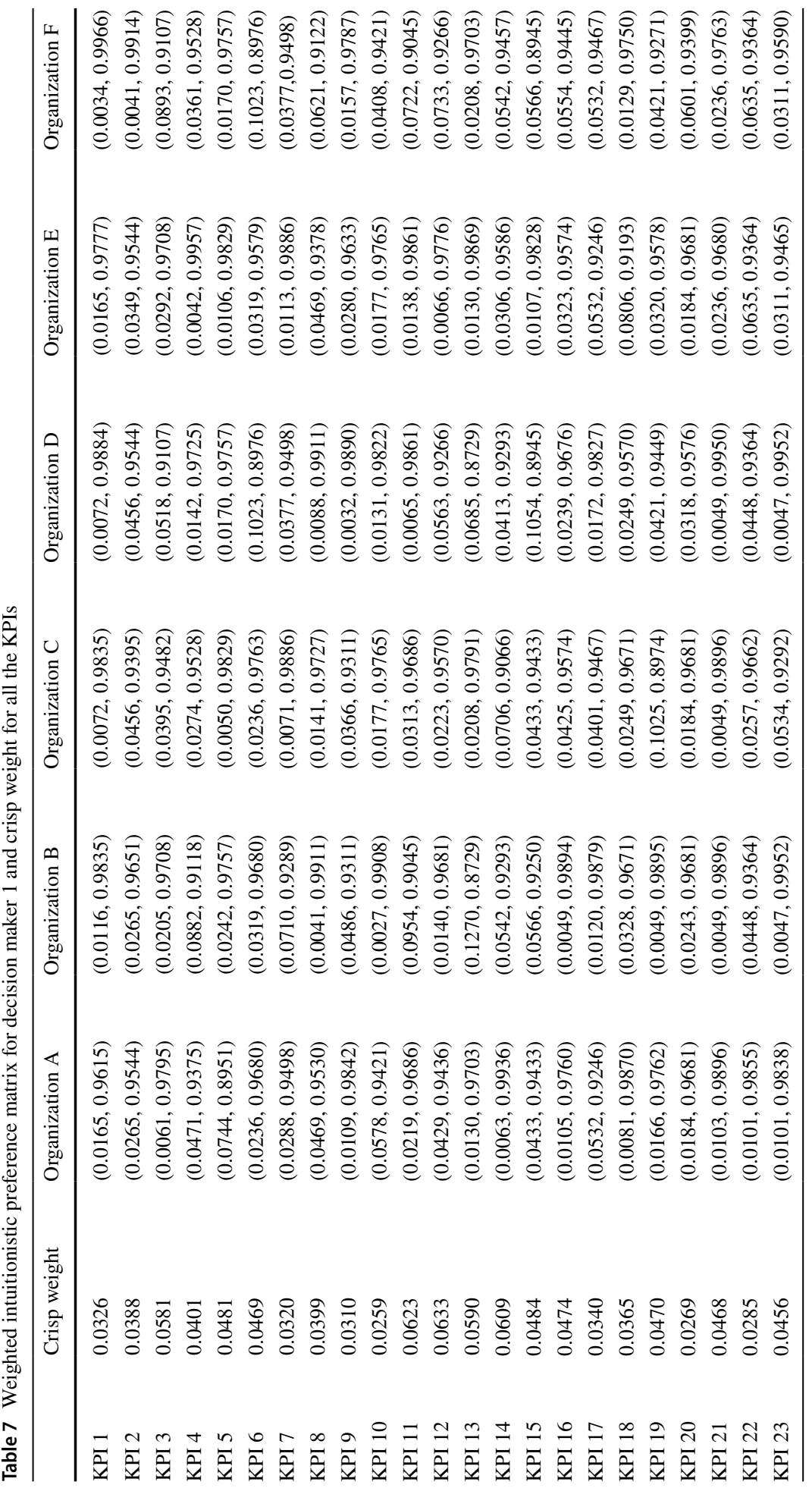


Table 8 Relative closeness of three decision makers and their respective weights

\begin{tabular}{lll}
\hline Decision maker & Relative closeness & Weight \\
\hline Decision maker 1, $t_{1}$ & $C^{t_{1}}=0.9764$ & $\xi^{t_{1}}=0.3337$ \\
Decision maker 2, $t_{2}$ & $C^{t_{2}}=0.9738$ & $\xi^{t_{2}}=0.3328$ \\
Decision maker 3, $t_{3}$ & $C^{t_{3}}=0.9754$ & $\xi^{t_{3}}=0.3334$ \\
\hline
\end{tabular}

respect to each alternative $Q_{s}$ is constructed using Eq. (26). The positive ideal solution $Q^{+}$ and two negative ideal solutions $Q_{c}^{-}$and $Q^{-}$are constructed considering the weighted intuitionistic decision matrix with respect to the alternatives and using Eqs. (27), (28) and (29). The positive and negative ideal decision matrices $Q^{+}, Q_{c}^{-}$and $Q^{-}$are presented in Table 9. The separation measures $D_{s}^{+}, D_{s}^{c}$ and $D_{s}^{-}$representing the separation of $Q_{s}$ from the positive ideal solution $Q^{+}$and two negative ideal solutions $Q_{c}^{-}$and $Q^{-}$respectively. The separation measures $D_{s}^{+}, D_{s}^{c}$ and $D_{s}^{-}$are determined using Eqs. (30), (31) and (32) respectively and presented in Table 10. Relative closeness associated with all the alternatives $C^{s}$ are computed using Eq. (33). Table 10 also provides the related closeness for different alternatives (organizations) and their corresponding ranking.

\subsection{Sensitivity analysis for robustness check}

Sensitivity analysis is performed for ensuring the robustness and feasibility of the proposed framework comprising of different methodologies including IF-AHP and IF-TOPSIS. The analysis aims to investigate about the impact of changing in the criteria weights on the priority results of the alternatives. It basically means that the sensitivity analysis is conducted by varying the crisp weights of the key performance indicators (KPIs) and accordingly studying their impact on the ranking of the alternatives. Decision maker's linguistic responses are used to derive the intuitionistic weights of the KPIs and which in turn are employed for obtaining the crisp weight of the KPIs. Moreover, linguistic responses of the decision makers might be subject to error due to the involvement of human judgement, therefore it is imperative to perform a sensitivity analysis to check the robustness and feasibility of the proposed system. For conducting the sensitivity analysis, certain experiments are created by interchanging the crisp weight of a particular KPI with another KPI and accordingly the ranking of the alternatives are obtained (Önüt et al. 2010; Zyoud et al. 2016)).

Based on the kind of sensitivity analysis suggested in the work of Önüt et al. (2010) and Zyoud et al. (2016), 12 combinations are generated by exchanging one criteria's weight with another. Three priority vectors pertaining to each of the decision makers containing intuitionistic fuzzy information associated with the KPIs are generated for performing the sensitivity analysis. Each experiment is denoted in a certain way to make it clear in understanding about which crisp weights of the KPIs are interchanged. For example- $-\mathrm{C} 15$ means that crisp weight of KPI 1 is exchanged with the crisp weight of KPI 5. Table 11 presents the results associated with the sensitivity analysis. The relative closeness coefficient for each of the alternatives are represented as CCA1, CCA2, CCA3, CCA4, CCA5 and CCA6. The value of the closeness coefficient and the ranking of the alternative are presented on Table 11. It is interesting to note that for all the 12 experiments, the alternatives A4 and A3 consistently changes the position among themselves as the first two ranked alternatives. Although, the ranking position of A1, A6, A5 and A2 remains same and their ranking order stays unchanged throughout the experiments. The internal coherence of the 


\begin{tabular}{|c|c|c|}
\hline 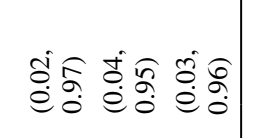 & 妾 & 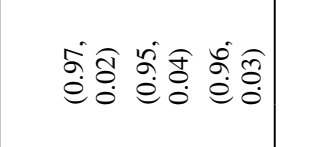 \\
\hline 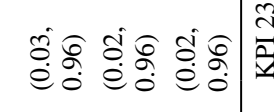 & | & 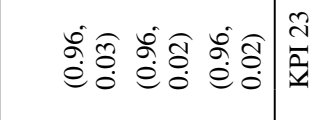 \\
\hline 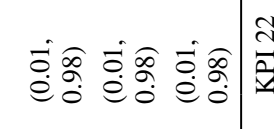 & 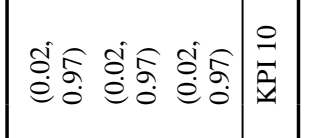 & 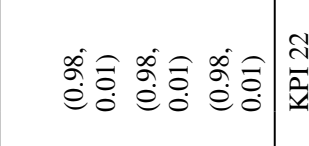 \\
\hline 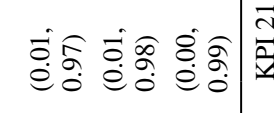 & 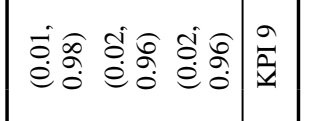 & 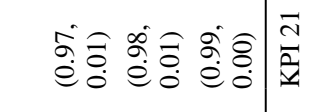 \\
\hline 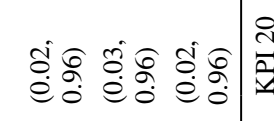 & 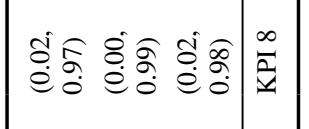 & 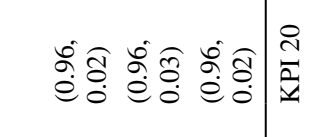 \\
\hline 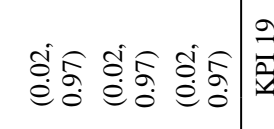 & 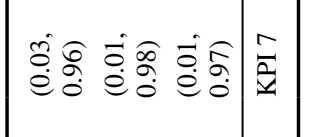 & 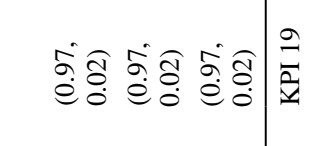 \\
\hline 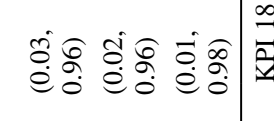 & 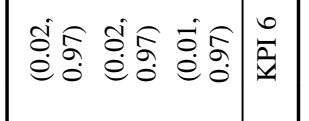 & 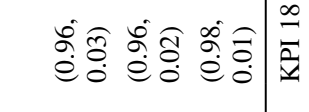 \\
\hline 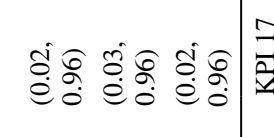 & 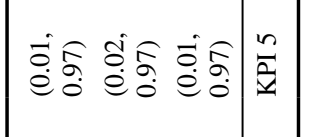 & 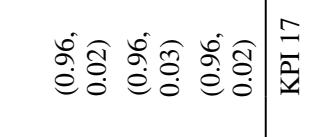 \\
\hline 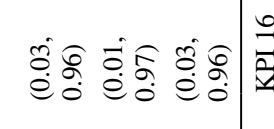 & 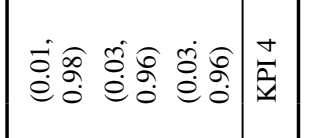 & 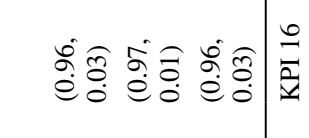 \\
\hline 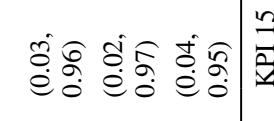 & 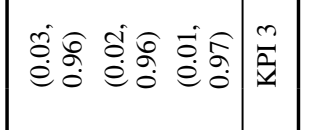 & 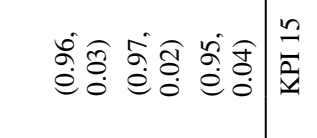 \\
\hline 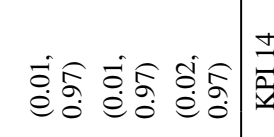 & 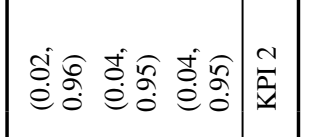 & 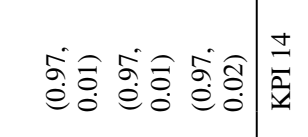 \\
\hline & & \\
\hline
\end{tabular}




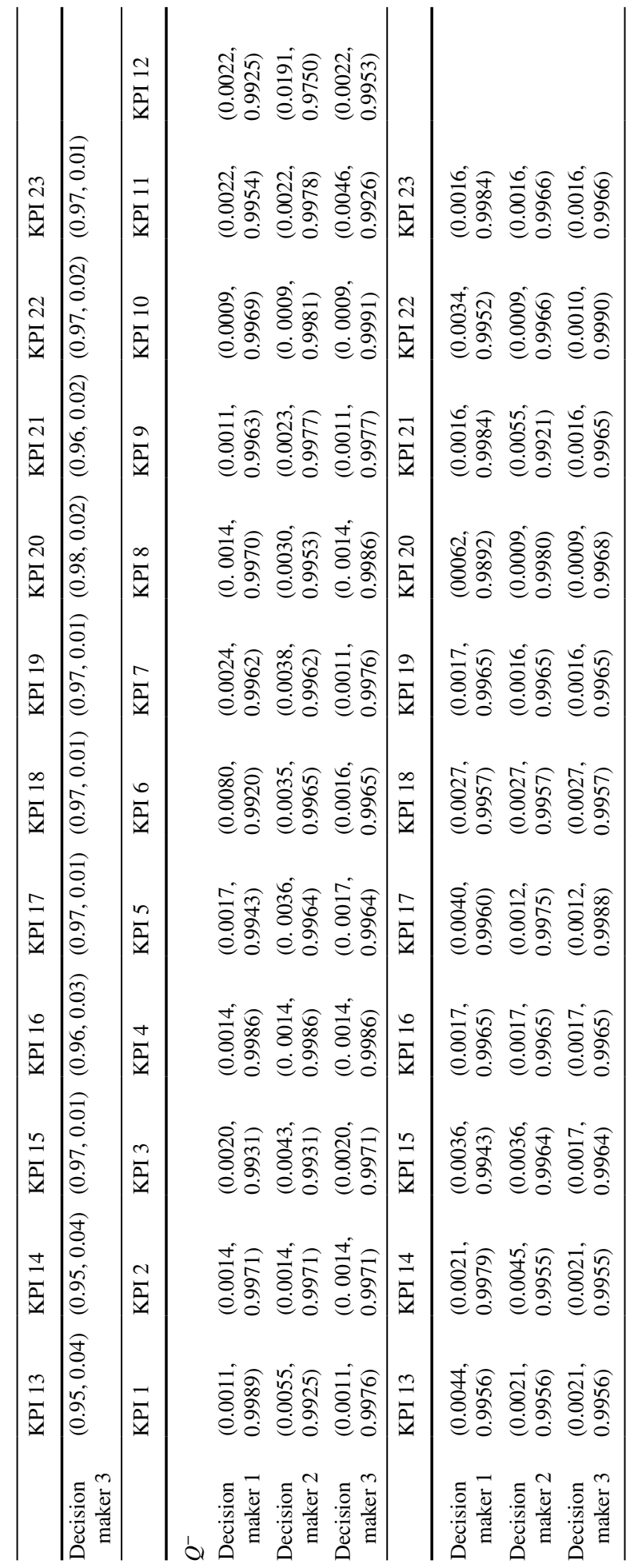


Table 10 Separation measures, relative closeness and ranking of the alternatives

\begin{tabular}{llllll}
\hline Organizations & \multicolumn{2}{l}{ Separation measures } & & $\begin{array}{l}\text { Relative closeness of each } \\
\text { alternative } C^{s}\end{array}$ & Ranking \\
\cline { 2 - 4 } & $D_{s}^{+}$ & $D_{s}^{c}$ & $D_{s}^{-}$ & & \\
\hline Organization A & 0.0152 & 0.9624 & 0.0109 & 0.9846 & 4 \\
Organization B & 0.0147 & 0.9620 & 0.0112 & 0.9851 & 3 \\
Organization C & 0.0118 & 0.9591 & 0.0142 & 0.9880 & 1 \\
Organization D & 0.0164 & 0.9637 & 0.0098 & 0.9834 & 6 \\
Organization E & 0.0159 & 0.9632 & 0.0098 & 0.9839 & 5 \\
Organization F & 0.0146 & 0.9619 & 0.0114 & 0.9852 & 2 \\
\hline
\end{tabular}

Table 11 Sensitivity analysis for validation of the proposed system

\begin{tabular}{|c|c|c|c|c|c|c|c|}
\hline \multirow[t]{2}{*}{ Experiment number } & \multicolumn{6}{|c|}{ Relative closeness of each alternative } & \multirow[t]{2}{*}{ Ranking order of the alternative } \\
\hline & CCA1 & $\mathrm{CCA} 2$ & $\mathrm{CCA} 3$ & CCA4 4 & CCA5 & CCA6 & \\
\hline $1-\mathrm{C} 15$ & 0.9760 & 0.9735 & 0.9823 & 0.9833 & 0.9753 & 0.9758 & $\mathrm{~A} 4>\mathrm{A} 3>\mathrm{A} 1>\mathrm{A} 6>\mathrm{A} 5>\mathrm{A} 2$ \\
\hline $2-\mathrm{C} 17$ & 0.9764 & 0.9613 & 0.9846 & 0.9855 & 0.9705 & 0.9743 & $\mathrm{~A} 4>\mathrm{A} 3>\mathrm{A} 1>\mathrm{A} 6>\mathrm{A} 5>\mathrm{A} 2$ \\
\hline $3-\mathrm{C} 25$ & 0.9788 & 0.9651 & 0.9838 & 0.9882 & 0.9689 & 0.9731 & $\mathrm{~A} 4>\mathrm{A} 3>\mathrm{A} 1>\mathrm{A} 6>\mathrm{A} 5>\mathrm{A} 2$ \\
\hline $4-\mathrm{C} 27$ & 0.9823 & 0.9734 & 0.9834 & 0.9863 & 0.9759 & 0.9793 & $\mathrm{~A} 4>\mathrm{A} 3>\mathrm{A} 1>\mathrm{A} 6>\mathrm{A} 5>\mathrm{A} 2$ \\
\hline $5-\mathrm{C} 35$ & 0.9765 & 0.9657 & 0.9820 & 0.9814 & 0.9692 & 0.9714 & $\mathrm{~A} 3>\mathrm{A} 4>\mathrm{A} 1>\mathrm{A} 6>\mathrm{A} 5>\mathrm{A} 2$ \\
\hline $6-\mathrm{C} 37$ & 0.9806 & 0.9753 & 0.9879 & 0.9843 & 0.9787 & 0.9794 & $\mathrm{~A} 3>\mathrm{A} 4>\mathrm{A} 1>\mathrm{A} 6>\mathrm{A} 5>\mathrm{A} 2$ \\
\hline $7-\mathrm{C} 45$ & 0.9774 & 0.9671 & 0.9889 & 0.9819 & 0.9738 & 0.9747 & $\mathrm{~A} 3>\mathrm{A} 4>\mathrm{A} 1>\mathrm{A} 6>\mathrm{A} 5>\mathrm{A} 2$ \\
\hline $8-\mathrm{C} 47$ & 0.9764 & 0.9669 & 0.9804 & 0.9787 & 0.9747 & 0.9756 & $\mathrm{~A} 3>\mathrm{A} 4>\mathrm{A} 1>\mathrm{A} 6>\mathrm{A} 5>\mathrm{A} 2$ \\
\hline $9-\mathrm{C} 55$ & 0.9866 & 0.9611 & 0.9874 & 0.9896 & 0.9710 & 0.9719 & $\mathrm{~A} 4>\mathrm{A} 3>\mathrm{A} 1>\mathrm{A} 6>\mathrm{A} 5>\mathrm{A} 2$ \\
\hline $10-\mathrm{C} 57$ & 0.9701 & 0.9630 & 0.9804 & 0.9839 & 0.9641 & 0.9679 & $\mathrm{~A} 44>\mathrm{A} 3>\mathrm{A} 1>\mathrm{A} 6>\mathrm{A} 5>\mathrm{A} 2$ \\
\hline $11-\mathrm{C} 65$ & 0.9815 & 0.9632 & 0.9834 & 0.9826 & 0.9748 & 0.9796 & $\mathrm{~A} 3>\mathrm{A} 4>\mathrm{A} 1>\mathrm{A} 6>\mathrm{A} 5>\mathrm{A} 2$ \\
\hline $12-\mathrm{C} 67$ & 0.9810 & 0.9609 & 0.9871 & 0.9867 & 0.9659 & 0.9700 & $\mathrm{~A} 3>\mathrm{A} 4>\mathrm{A} 1>\mathrm{A} 6>\mathrm{A} 5>\mathrm{A} 2$ \\
\hline
\end{tabular}

proposed system is validated by performing this sensitivity analysis which highlights the fact that the ranking of the alternative remain same.

\subsection{Implications}

From Table 10, it can be interpreted that organization $\mathrm{C}$ of the organization possesses the highest rank followed by organizations $\mathrm{F}$ and $\mathrm{B}$. The relative closeness coefficient of organizations $\mathrm{F}$ and $\mathrm{B}$ are nearly same with a different of 0.0001 in magnitude. Considering Tables 5 and 10, it must be noted that the organization B performs well in both the cases. Although, organization D occupies the last position in terms of ranking (from Table 10) and the total performance score of organization D is the lowest (from Table 5) when compared with other organizations. Therefore, more emphasis should be given in the development of organization D by improving certain aspects such as return on investment, stakeholder's involvement, labour efficiency, training rates and quality of employee life.

The research work performed in this paper contributes to the area of operations management by proposing a novel multi criteria decision making method by integrating 
intuitionistic fuzzy AHP and intuitionistic Fuzzy TOPSIS. To the best of author's knowledge, none of the multi-criteria decision-making techniques proposed in the literature combined IF-AHP and IF-TOPSIS which is proposed in this paper. The proposed methodology estimates the importance of the Key Performance Indicators and determines the performance of different organizations. The application of methodology is new to the field of sustainable development and it provides several opportunities to apply this proposed method in other context pertaining to closed loop supply chain management or supply chain resilience. This research also possesses teaching implication by giving awareness of this novel method to business, engineering and operations management students.

\section{Conclusion}

The proposed research contributes to bridging the research gap between literature and industrial practice in identifying the KPIs explicitly applicable to sustainable supply chain management for assessing the performance of the organizations. Several researchers in the past focused on performance assessment of green supply chain management (Fahimnia et al. 2015), supplier sustainability assessment Govindan et al. (2013) and others focussed specifically on environmental or economic aspects separately Dubey et al. (2015) and Barbosa-Póvoa et al. (2018). However, the proposed research addressed the research gaps by holistically considering all three dimensions of sustainability and identifying a set of KPIs for environmental, economic and social dimensions by performing a rigorous mixed method approach including literature survey and analysis of industrial practices. Moreover, a novel sustainability assessment framework using integrated intuitionistic fuzzy-based methodologies for assessing organizations performance is proposed. Intuitionistic fuzzy methodologies are employed to address another research gap in the literature, which suggest a lack of appropriate research considering the human judgement aspect within decision making.

The first part of the sustainability assessment framework obtains a revised list of KPIs from the initial set of KPIs by considering the expert judgements while performing Values Focus Thinking (VFT) and adopting a robust methodology named intuitionistic fuzzy analytic hierarchy process (IFAHP) for obtaining the weights of the identified KPIs. In the second part, these intuitionistic fuzzy weights of the KPIs are subsequently utilized in the proposed sustainability assessment framework for evaluating the performance of the KPIs for different organizations. The sustainability performance of various organizations is ranked using identified KPIs and intuitionistic fuzzy TOPSIS method.

The feasibility of the proposed framework is illustrated through its application to UK based firms. The data is collected in linguistic variables from the experts belonging to the UK manufacturing organizations. Moreover, the proposed sustainability framework has facilitated the identification of KPIs, their weighting and utilization to aid supply chain managers in evaluating and improving their organization's sustainability performance. Several insights and recommendations are provided regarding the improvement of the performance of the organizations on specific KPIs. The proposed decision-making framework for sustainability is convenient for the supply chain managers as the input can be provided in linguistic data and complex model of the decision support framework provides robust and appropriate results as shown in the sensitivity analysis. It is thus imperative for the organizations to adopt the concepts brought forth through this research work for continually evaluating and improving their supply chain sustainability. 
In future, the research can be extended by employing other robust MCDM methodologies combined with the intuitionistic fuzzy set for determining the weights of the KPIs. Furthermore, there is potential for the development of a decision support system based on the proposed sustainability assessment framework which could assess, identify hot spots, improve and provide managerial decision-making support to the supply chain managers.

Acknowledgements This research has been funded through the UK-India Education and Research Initiative UKIERI-UGC funded Project "Advanced Analytics for Green and Resilient Supply Chain Decision Making” Grant Contract Number: UGC UKIERI 2016-17-067.

Funding Funding was provided by UK-India Education and Research Initiative.

Open Access This article is distributed under the terms of the Creative Commons Attribution 4.0 International License (http://creativecommons.org/licenses/by/4.0/), which permits unrestricted use, distribution, and reproduction in any medium, provided you give appropriate credit to the original author(s) and the source, provide a link to the Creative Commons license, and indicate if changes were made.

\section{References}

Ahi, P., \& Searcy, C. (2015). Assessing sustainability in the supply chain: A triple bottom line approach. Applied Mathematical Modelling, 39(10-11), 2882-2896.

Alexander, A., Walker, H., \& Naim, M. (2014). Decision theory in sustainable supply chain management: A literature review. Supply Chain Management: An International Journal, 19(5/6), 504-522.

Allevi, E., Gnudi, A., Konnov, I. V., \& Oggioni, G. (2018). Evaluating the effects of environmental regulations on a closed-loop supply chain network: A variational inequality approach. Annals of Operations Research, 261(1-2), 1-43.

Asefi, H., Lim, S., Maghrebi, M., \& Shahparvari, S. (2019). Mathematical modelling and heuristic approaches to the location-routing problem of a cost-effective integrated solid waste management. Annals of Operations Research, 273(1-2), 75-110.

Balfaqih, H., Nopiah, Z. M., Saibani, N., \& Al-Nory, M. T. (2016). Review of supply chain performance measurement systems: 1998-2015. Computers in Industry, 82, 135-150.

Banasik, A., Bloemhof-Ruwaard, J. M., Kanellopoulos, A., Claassen, G. D. H., \& van der Vorst, J. G. (2016). Multi-criteria decision making approaches for green supply chains: A review. Flexible Services and Manufacturing Journal, 30(3), 366-396.

Barbosa-Póvoa, A. P., da Silva, C., \& Carvalho, A. (2018). Opportunities and challenges in sustainable supply chain: An operations research perspective. European Journal of Operational Research, 268(2), 399-431.

Beamon, B. M., \& Chen, V. C. (2001). Performance analysis of conjoined supply chains. International Journal of Production Research, 39(14), 3195-3218.

Belton, V., \& Stewart, T. (2010). Problem structuring and MCDA. In M. Ehrgott, J. Figueira, \& S. Greco (Eds.), Trends in multiple criteria decision analysis (pp. 209-239). Berlin: Springer.

Cao, Q., Wu, J., \& Liang, C. (2015). An intuitionistic fuzzy judgement matrix and TOPSIS integrated multi-criteria decision making method for green supplier selection. Journal of Intelligent \& Fuzzy Systems, 28(1), 117-126.

Chai, J., Liu, J. N., \& Ngai, E. W. (2013). Application of decision-making techniques in supplier selection: A systematic review of literature. Expert Systems with Applications, 40(10), 3872-3885.

Chakraborty, K., Mondal, S., \& Mukherjee, K. (2019). Critical analysis of enablers and barriers in extension of useful life of automotive products through remanufacturing. Journal of Cleaner Production, 227, 1117-1135.

Chan, F. T. S. (2003). Performance measurement in a supply chain. The International Journal of Advanced Manufacturing Technology, 21(7), 534-548.

Chang, K. H. (2017). A novel supplier selection method that integrates the intuitionistic fuzzy weighted averaging method and a soft set with imprecise data. Annals of Operations Research, 272(1), 139-157.

Chardine-Baumann, E., \& Botta-Genoulaz, V. (2014). A framework for sustainable performance assessment of supply chain management practices. Computers \& Industrial Engineering, 76, 138-147. 
Chen, L., Zhao, X., Tang, O., Price, L., Zhang, S., \& Zhu, W. (2017). Supply chain collaboration for sustainability: A literature review and future research agenda. International Journal of Production Economics, 194, 73-87.

Cheng, C. I., \& Liu, D. S. M. (2007). A decision making framework for dressing consultant. In IEEE symposium on computational intelligence in multicriteria decision making (pp. 267-271). IEEE.

Cheng, P., Zhou, B., Chen, Z., \& Tan, J. (2017). The TOPSIS method for decision making with 2-tuple linguistic intuitionistic fuzzy sets. In 2017 IEEE 2nd advanced information technology, electronic and automation control conference (IAEAC) (pp. 1603-1607). IEEE.

Dangelico, R. M., \& Pujari, D. (2010). Mainstreaming green product innovation: Why and how companies integrate environmental sustainability. Journal of Business Ethics, 95(3), 471-486.

De Brucker, K., Macharis, C., \& Verbeke, A. (2013). Multi-criteria analysis and the resolution of sustainable development dilemmas: A stakeholder management approach. European Journal of Operational Research, 224(1), 122-131.

Deshmukh, S. P., \& Sunnapwar, V. K. (2013). Validation of performance measures for green supplier selection in Indian industries. International Journal of Modeling and Engineering Resources, 3, 1617-1622.

Dev, N. K., Shankar, R., Gunasekaran, A., \& Thakur, L. S. (2016). A hybrid adaptive decision system for supply chain reconfiguration. International Journal of Production Research, 54(23), 7100-7114.

Dong, J., Yang, D. Y., \& Wan, S. P. (2015). Trapezoidal intuitionistic fuzzy prioritized aggregation operators and application to multi-attribute decision making. Iranian Journal of Fuzzy Systems, 12(4), 1-32.

Dubey, R., Gunasekaran, A., \& Ali, S. S. (2015). Exploring the relationship between leadership, operational practices, institutional pressures and environmental performance: A framework for green supply chain. International Journal of Production Economics, 160, 120-132.

Esmaeilikia, M., Fahimnia, B., Sarkis, J., Govindan, K., Kumar, A., \& Mo, J. (2016). Tactical supply chain planning models with inherent flexibility: Definition and review. Annals of Operations Research, 244(2), 407-427.

Fahimnia, B., Sarkis, J., \& Davarzani, H. (2015). Green supply chain management: A review and bibliometric analysis. International Journal of Production Economics, 162, 101-114.

Garg, D., Luthra, S., \& Haleem, A. (2014). Ranking of performance measures of GSCM towards sustainability: Using analytic hierarchy process. World Academy of Science, Engineering and Technology - International Journal of Social, Human Science and Engineering, 8(3), 743-749.

Genovese, A., Lenny Koh, S. C., Kumar, N., \& Tripathi, P. K. (2014). Exploring the challenges in implementing supplier environmental performance measurement models: A case study. Production Planning \& Control, 25(13-14), 1198-1211.

Ghosh, D., Shah, J., \& Swami, S. (2018). Product greening and pricing strategies of firms under green sensitive consumer demand and environmental regulations. Annals of Operations Research, 1, 1-30.

Govindan, K., Agarwal, V., Darbari, J. D., \& Jha, P. C. (2017). An integrated decision making model for the selection of sustainable forward and reverse logistic providers. Annals of Operations Research (pp. 1-44).

Govindan, K., \& Jepsen, M. B. (2016). Supplier risk assessment based on trapezoidal intuitionistic fuzzy numbers and ELECTRE TRI-C: A case illustration involving service suppliers. Journal of the Operational Research Society, 67(2), 339-376.

Govindan, K., Khodaverdi, R., \& Jafarian, A. (2013). A fuzzy multi criteria approach for measuring sustainability performance of a supplier based on triple bottom line approach. Journal of Cleaner Production, 47, 345-354.

Gunasekaran, A., \& Kobu, B. (2007). Performance measures and metrics in logistics and supply chain management: A review of recent literature (1995-2004) for research and applications. International Journal of Production Research, 45(12), 2819-2840.

Gunasekaran, A., Patel, C., \& Tirtiroglu, E. (2001). Performance measures and metrics in a supply chain environment. International Journal of Operations \& Production Management, 21(1/2), 71-87.

Hofer, C., Cantor, D. E., \& Dai, J. (2012). The competitive determinants of a firm's environmental management activities: Evidence from US manufacturing industries. Journal of Operations Management, 30(1-2), 69-84.

Hussain, M., Awasthi, A., \& Tiwari, M. K. (2016). Interpretive structural modeling-analytic network process integrated framework for evaluating sustainable supply chain management alternatives. Applied Mathematical Modelling, 40(5-6), 3671-3687.

Iraldo, F., Testa, F., \& Frey, M. (2009). Is an environmental management system able to influence environmental and competitive performance? The case of the eco-management and audit scheme (EMAS) in the European Union. Journal of Cleaner Production, 17(16), 1444-1452.

Isaksson, R., Johansson, P., \& Fischer, K. (2010). Detecting supply chain innovation potential for sustainable development. Journal of Business Ethics, 97(3), 425-442. 
Kaplan, R. S. \& Norton, D. P. (1996). Balanced Scorecard. In Das Summa Summarum des Management (pp. 137-148). Wiesbaden: Gabler. Retrieved from http:/www.springerlink.com/index /10.1007/978-3-8349-9320-5_12.

Keeney, R. L. (1996). Value-focused thinking: Identifying decision opportunities and creating alternatives. European Journal of Operational Research, 92(3), 537-549.

Khidir, T. A., \& Zailani, S. H. M. (2011). Greening of the supply chain through supply chain initiatives towards environmental sustainability. The Journal of Global Business Management. ISSN 1817, 3197.

Korpela, J., Lehmusvaara, A., \& Tuominen, M. (2001). An analytic approach to supply chain development. International Journal of Production Economics, 71(1-3), 145-155.

Li, Y., Kannan, D., Jha, P. C., Garg, K., Darbari, J., \& Agarwal, N. (2018). Design of a multi echelon product recovery embeded reverse logistics network for multi products and multi periods. Annals of Operations Research (pp. 1-22).

Maestrini, V., Luzzini, D., Maccarrone, P., \& Caniato, F. (2017). Supply chain performance measurement systems: A systematic review and research agenda. International Journal of Production Economics, 183, 299-315.

Mathivathanan, D., Kannan, D., \& Haq, A. N. (2018). Sustainable supply chain management practices in Indian automotive industry: A multi-stakeholder view. Resources, Conservation and Recycling, 128, 284-305.

Montabon, F., Sroufe, R., \& Narasimhan, R. (2007). An examination of corporate reporting, environmental management practices and firm performance. Journal of Operations Management, 25(5), 998-1014.

Morali, O., \& Searcy, C. (2013). A review of sustainable supply chain management practices in Canada. Journal of Business Ethics, 117(3), 635-658.

Olugu, E. U., Wong, K. Y., \& Shaharoun, A. M. (2011). Development of key performance measures for the automobile green supply chain. Resources, Conservation and Recycling, 55(6), 567-579.

Önüt, S., Efendigil, T., \& Kara, S. S. (2010). A combined fuzzy MCDM approach for selecting shopping center site: An example from Istanbul, Turkey. Expert Systems with Applications, 37(3), 1973-1980.

Oyemomi, O., Liu, S., Neaga, I., \& Alkhuraiji, A. (2016). How knowledge sharing and business process contribute to organizational performance: Using the fsQCA approach. Journal of Business Research, $69(11), 5222-5227$.

Qu, G., et al. (2017). Choquet integral correlation coefficient of intuitionistic fuzzy sets and its applications. Journal of Intelligent \& Fuzzy Systems, 33(1), 543-553.

Reh, F. J. (2016). What you need to know about key performance indicators. The balance. Retrieved from https://www.thebalance.com/key-performance-indicators-2275156.

Santiteerakul, S., Sekhari, A., Bouras, A., \& Sopadang, A. (2015). Sustainability performance measurement framework for supply chain management. International Journal of Product Development, 20(3), 221-238.

Seuring, S., \& Müller, M. (2008). From a literature review to a conceptual framework for sustainable supply chain management. Journal of Cleaner Production, 16(15), 1699-1710.

Shaharudin, M. R., Govindan, K., Zailani, S., Tan, K. C., \& Iranmanesh, M. (2017). Product return management: Linking product returns, closed-loop supply chain activities and the effectiveness of the reverse supply chains. Journal of Cleaner Production, 149, 1144-1156.

Shen, F., Xu, J., \& Xu, Z. (2015). An automatic ranking approach for multi-criteria group decision making under intuitionistic fuzzy environment. Fuzzy Optimization and Decision Making, 14(3), 311-334.

Shepherd, C., \& Günter, H. (2010). Measuring supply chain performance: Current research and future directions. In Behavioral Operations in Planning and Scheduling (pp. 105-121). Springer, Berlin.

Soheilirad, S., Govindan, K., Mardani, A., Zavadskas, E. K., Nilashi, M., \& Zakuan, N. (2017). Application of data envelopment analysis models in supply chain management: A systematic review and metaanalysis. Annals of Operations Research, (pp. 1-55).

Taleizadeh, A. A., Govindan, K., \& Ebrahimi, N. (2018). The effect of promotional cost sharing on the decisions of two-level supply chain with uncertain demand. Annals of Operations Research (pp. 1-35).

Tan, K. H., Zhan, Y., Ji, G., Ye, F., \& Chang, C. (2015). Harvesting big data to enhance supply chain innovation capabilities: An analytic infrastructure based on deduction graph. International Journal of Production Economics, 165, 223-233.

Taticchi, P., Tonelli, F., \& Pasqualino, R. (2013). Performance measurement of sustainable supply chains. International Journal of Productivity and Performance Management, 62(8), 782-804.

Tooranloo, Hossein Sayyadi, \& Iranpour, A. (2017). Supplier selection and evaluation using interval-valued intuitionistic fuzzy AHP method. International Journal of Procurement Management, 10, 539-554.

Tooranloo, H. S., \& sadat Ayatollah, A. (2016). A model for failure mode and effects analysis based on intuitionistic fuzzy approach. Applied Soft Computing, 49, 238-247. 
Wang, G., \& Gunasekaran, A. (2017). Modeling and analysis of sustainable supply chain dynamics. Annals of Operations Research, 250(2), 521-536.

Xu, Z., \& Liao, H. (2014). Intuitionistic fuzzy analytic hierarchy process. IEEE Transactions on Fuzzy Systems, 22(4), 749-761.

Yawar, S. A., \& Seuring, S. (2017). Management of social issues in supply chains: A literature review exploring social issues, actions and performance outcomes. Journal of Business Ethics, 141(3), 621-643.

Yue, Z. (2014). TOPSIS-based group decision-making methodology in intuitionistic fuzzy setting. Information Sciences, 277, 141-153.

Zyoud, S. H., Kaufmann, L. G., Shaheen, H., Samhan, S., \& Fuchs-Hanusch, D. (2016). A framework for water loss management in developing countries under fuzzy environment: Integration of Fuzzy AHP with Fuzzy TOPSIS. Expert Systems with Applications, 61, 86-105.

Publisher's Note Springer Nature remains neutral with regard to jurisdictional claims in published maps and institutional affiliations.

\title{
Affiliations
}

\author{
Alok Choudhary $^{1}$ (D) Arijit De $^{2} \cdot$ Karim Ahmed $^{3} \cdot$ Ravi Shankar $^{1,4}$ \\ Alok Choudhary \\ a.choudhary@lboro.ac.uk \\ 1 School of Business and Economics, Loughborough University, Loughborough LE11 3TU, UK \\ 2 Newcastle University Business School, Newcastle University, Newcastle upon Tyne NE1 4SE, UK \\ 3 School of Mechanical, Aerospace and Automotive Engineering, Coventry University, \\ Coventry CV1 2JH, UK \\ 4 Department of Management Studies, Indian Institute of Technology, Delhi, New Delhi, India
}

